\title{
1st Congress of the International Society of Nutrigenetics/Nutrigenomics (ISNN)
}

November 11-13, 2007, Athens, Greece
Guest Editor

Artemis P. Simopoulos, Washington, D.C.

\section{Contents}

Oral Presentations

Plenary Lectures

Abstracts A1-A5

Session I: Genetic Variation and Dietary Response in Cardiovascular Disease

Abstracts A6-A9

Session II: Gene-Nutrient Interactions and Hypertension Abstracts A10-A12

Session III: Gene-Nutrient Interactions and Osteoporosis Abstracts A13-A14

Session IV: Genetics and Obesity

Abstracts A15-A19

Session V: Genetics of Cancer

Abstracts A20-A23

Session VI: Genetics of Diabetes

Abstracts A24-A26

Session VII: Industry and Consumers - What Is the

Business Model for Personalized Nutrition and Medicine? Abstracts A27-A32

\section{Poster Presentations}

Abstracts P1-P33 


\section{Journal of \\ Nutrigenetics \\ Nutrigenomics}

\section{Plenary Lectures}

\section{A1 \\ Nutrigenetics/Nutrigenomics: Nutritional Implications}

\section{A.P. Simopoulos \\ The Center for Genetics, Nutrition and Health and the International Society of Nutrigenetics/Nutrigenomics, Washington, DC, USA}

The interaction of genetics and environment, nature, and nurture is the foundation for all health and disease. In the last two decades, using the techniques of molecular biology, it has been shown that genetic factors determine susceptibility to disease and environmental factors determine which genetically susceptible individuals will be affected. Nutrition is an environmental factor of major importance. Whereas major changes have taken place in our diet over the past 10,000 years since the beginning of the Agricultural Revolution, our genes have not changed. The spontaneous mutation rate for nuclear DNA is estimated at $0.5 \%$ per million years. Therefore, over the past 10,000 years there has been time for very little change in our genes, perhaps $0.005 \%$. In fact, our genes today are very similar to the genes of our ancestors during the Paleolithic period 40,000 years ago, at which time our genetic profile was established. Genetically speaking, humans today live in a nutritional environment that differs from that for which our genetic constitution was selected. A high omega-6/omega-3 ratio, as is found in today's Western diets, promotes the pathogenesis of many chronic diseases, including cardiovascular disease, diabetes, asthma, and possibly cancer. Increased dietary intake of linoleic acid (LA) leads to oxidation of low-density lipoprotein (LDL), platelet aggregation, and interferes with the incorporation of essential fatty acids (EFA) in cell membrane phopholipids. Both omega- 6 and omega-3 fatty acids influence gene expression. Omega-3 fatty acids have strong anti-inflammatory effects, suppress interleukin $1 \beta$ (IL-1 $\beta$ ), tumor necrosis factor- $\alpha$ (TNF $\alpha$ ) and interleukin-6 (IL-6), whereas omega- 6 fatty acids tend to be pro-inflammatory. Because inflammation is at the base of many chronic diseases, including coronary heart disease, dietary intake of omega-3 fatty acids plays an important role in the manifestation of disease, particularly in persons with genetic variation, as for example in individuals with genetic variants at the 5-lipoxygenase (5-LO). Increased dietary arachidonic acid (AA) significantly enhances the apparent atherogenic effect of genotype, whereas increased dietary intake of omega-3 fatty acids eicosapentaenoic acid (EPA) and docosahexaenoic acid (DHA) blunts this effect. The diet-gene interaction further suggests that dietary omega-6 fatty acids promote, whereas marine omega-3 fatty acids EPA and DHA inhibit leukotriene-mediated inflammation that leads to atherosclerosis in this subpopulation. Because chronic diseases are multi- genic and multifactorial, it is quite possibly that the therapeutic dose of omega-3 fatty acids will depend on the degree of severity of disease resulting from the genetic predisposition. Knowing who is at risk would be useful if it meant that one could avoid the environmental triggers that convert susceptibility to disease. The prospect of targeting specific dietary treatment to those predicted to gain the most therapeutic benefit clearly has important clinical and economic consequences, particularly in diseases of high prevalence such as coronary artery disease, hypertension, diabetes, osteoporosis, and possibly cancer. There is no single universal approach for what we are calling the "lifestyle" approach to diseases with genetic predisposition. The approach will have to vary with national dietary patterns and national economy. Therefore, it will be necessary to promote lifestyle patterns that will be compatible with a healthier phenotypic expression of genotypes evolved under different conditions, which means individualized prescriptions and gene-based designer diets.

\section{A2 \\ Nutriepigenomics: A Lifelong Stochastic, Genetic \& Environmental Remodeling of Our Epigenome}

\author{
C. Junien, C. Gallou-Kabani, A. Vigé
}

Inserm U781 - Genetics and epigenetics of metabolic diseases, neurosensorial diseases and development Hôpital Necker Enfants-Malades, Paris, France

The phenotype of an individual is the result of complex interactions between genotype, epigenome and current, past and ancestral environment leading to a lifelong remodelling of our epigenomes. Depending on the nature and intensity of the insult, the critical spatiotemporal windows and developmental or lifelong processes involved, these epigenetic alterations can lead to permanent changes in tissue and organ structure and function, or, to reversible changes, using appropriate epigenetic tools, and often with sexually dimorphic effects. Moreover, poorly adapted behavior or lifestyle and desynchronized cues may disturb the circadian epigenetic modulation of gene expression and result in functional asynchrony in the body as a whole. Thus epimutations accumulate over time, increasing the "epigenetic burden" potentially leading to the onset of age- and/or environment-related diseases. Given the significant and increasing proportion of women who are overweight and overfed when pregnant this represents a major health concern for future generations. In order to identify stochastically, genetically and environmentally triggered epigenetic changes we have developped several murine models with different genetic backgrounds - under different nutritional conditions, at different stages of development - that led us:: 1) - to describe an unexpected environmentally triggered resistance to a high-fat diet (HFD); 2) - to show that - in genetically identical mice - early random stochastic events could also lead to different metabolic

\begin{tabular}{ll}
\hline KARGER & ( ) 2007 S. Karger AG, Basel \\
1661-6499/08/0012-0059\$24.50/0 \\
$\begin{array}{l}\text { Fax +4161306 1234 } \\
\text { E-Mail karger@karger.ch } \\
\text { www.karger.com }\end{array}$ & $\begin{array}{l}\text { Accessible online at: } \\
\text { www.karger.com/jnn }\end{array}$
\end{tabular}


adaptation and predestinate to resistance to a HFD; 3) - to detect alterations of placental gene-expression in mouse and rat models fed a HFD or a restricted protein diet. Transcriptome, QRTPCR, and global and gene-specific DNA methylation analyses have allowed us to focus on pathways involved in satiety, lipid and carbohydrate transport and metabolism, in relation with circadian rhythms and nuclear receptors, and in relation with imprinted genes and the epigenetic machinery. Given several encouraging trials, prevention and therapy of age- and lifestyle- related diseases by individualized tailoring to optimal epigenetic diets or drugs are conceivable. However this will require intense efforts to unravel the complexity of these epigenetic, genetic and environmental interactions and to evaluate their potential reversibility with minimal side effects

\section{A3 \\ Proteomics Strategies and Applications for Nutritional Research}

\author{
G.S. Omenn \\ University of Michigan, Ann Arbor, Michigan, USA
}

Nutritional variables are major perturbations to biological systems, from cells to whole organisms. The modern 'omics technologies are well-suited to explore signaling and metabolic pathways and regulatory networks that respond to such environmental stressors; to identify panels of biomarkers (methylation, mRNAs, miRNAs, proteins, metabolites) of health and disease; to predict targets for dietary interventions; and to elucidate genetic variation in responses, a precursor to personalized or individualized healthcare. This lecture focuses on nutri-proteomics analyses of organs and plasma specimens. Europe has taken the lead in this work, in part through the Network of Excellence for Nutrigenomics (NuGO). Proteomics is the link between gene expression and metabolic pathways. Proteomics analyses of nutritional perturbations have been slow to emerge in the literature due to specimen complexity, extreme dynamic range of protein concentrations, laborious methods, and lack of a full catalog of human proteins. Examples include vitamin B12 deficiency effects seen in the CSF proteome, reversed with cobalamin; zinc deficiencyinduced oxidative stress and lipid metabolism proteins; striking liver proteome differences between susceptible C57BL/6 and resistant $\mathrm{C} 3 \mathrm{H}$ mouse strains in response to an atherogenic diet; and Genistein anti-atherosclerotic activity in endothelial cells stressed with oxidized LDL or with homocysteine. Proteomics has revealed great detail about intracellular organelles, including mitochondria, zymogen granules, and the secretory pathway from rough to smooth ER to Golgi to cell surface. These proteomes will be useful in analyses of inherited human disorders of mitochondria and secretory pathways as influenced by different diets.

[Supported by MTTC grant 687 and NIH 1U54DA021519].

\section{A4}

\section{Metabolomics in Health and Disease}

D.M. Mutch

INSERM UMRS U872 (Eq 7) Nutriomique, Paris, France

Metabolomics is a logical compliment to the fields of transcriptomics and proteomics by providing additional insight into the underlying biochemistry of an organism. Indeed, metabolomics is now thought to be the 'omic platform most representative of phenotype. While this concept is becoming more and more accepted by the scientific community, the field of metabolomics continues to face many of the challenges previously encountered in gene and protein expression studies. Potentially massive datasets are produced within a single experiment, meaning that data analysis and interpretation can be major obstacles. Furthermore, while accurate and quantitative measurements can be made, the human metabolome is not yet fully characterized; therefore identifying a novel metabolite can present a significant challenge. Nevertheless, the use of metabolomics in nutrition and health management is unquestionable and will play an important role in optimizing health through personalized diets and medicine. This presentation will introduce the exciting field of metabolomics and demonstrate its use in health management.

\section{A5 \\ Role of Nutrients in Gene Expression - Omega-3 Fatty Acids and the Regulation of Endothelial COX-2}

\author{
R. De Caterina ${ }^{1}$, M. Massaro ${ }^{2}$, R. Madonna ${ }^{1}$ \\ ${ }^{1} \mathrm{G}$. d'Annunzio" University - Chieti, and ${ }^{2} \mathrm{CNR}$ Institute of \\ Clinical Physiology - Pisa, Italy
}

Effects on endothelial-leukocyte interactions provide particularly compelling examples of how n-3 PUFAs may impact atherogenesis. We demonstrated inhibition of NF- $\mathrm{kB}$ activation by DHA (the most potent fatty acid inhibitor of endothelial activation), which paralleled production of hydrogen peroxide by cultured endothelial cells. This reactive oxygen species (or one of its downstream unstable products) appears to be a critical mediator of NF- $\mathrm{kB}$ activation. Both baseline production and IL-1 or TNF-stimulated production of intracellular hydrogen peroxide (and its downstream products) were reduced after cell membrane enrichment with DHA. Saturated fatty acids served as a negative control in these experiments. Cyclooxygenase (COX)-2 is responsible for the overproduction of prostaglandins (PG) at inflammatory sites and its expression is increased in human atheroma. We recently reported on the effects of DHA on COX-2 expression and activity in human saphenous vein endothelial (HSVEC) cells challenged with proinflammatory stimuli. A $>24$-hour exposure to DHA reduced COX-2 expression and activity in HSVEC induced by interleukin (IL)-1, without affecting COX-1 expression. DHA effect was dependent on the Nuclear Factor (NF)-кB binding site in the COX-2 promoter. Electrophoretic mobility shift assays confirmed that DHA attenuated NF-kappaB activation. Since mitogen-activated protein kinases, protein kinase-C (PKC), and $\mathrm{NAD}(\mathrm{P}) \mathrm{H}$ oxidase all participate in IL-1 mediated COX-2 expression, we also tested whether 
these enzymes were involved in DHA effects. Western analyses showed that DHA blocked nuclear p65 NF-kappaB subunit translocation by decreasing cytokine-stimulated reactive oxygen species (ROS) and ERK1/2 activation via effects on both NAD $(\mathrm{P}) \mathrm{H}$ oxidase and PKCepsilon activities. Because COX-2 overexpression in atherosclerosis appears linked to plaque instability, these studies provide a mechanism for plaque-stabilizing effects of DHA. Our current overall hypothesis is that fatty acid peroxidability, determined by the presence and number of double bonds, of the membrane fatty acids is directly related to endothelial cell responses.

\section{Session I: Genetic Variation and Dietary Response in Cardiovascular Disease}

\section{A6 \\ Gene:Environment Interaction on Coronary Heart Disease (CHD) Risk}

\author{
P.J. Talmud, J.A. Cooper, S.E. Humphries \\ University College London, London, UK
}

Background: In understanding the development of CHD, the modifying effects of environmental factors on an individual's genotype is particularly important. Since both smoking and APOE have been associated with increased CHD risk, we examined whether the impact of smoking on CHD risk was influenced by APOE genotype.

Results: In the prospective Northwick Park Heart Study (NPHSII), the hazard ratio (HR) of smoking alone on CHD risk was1.94 (1.25-3.01). APOE genotype was associated with usual effects on cholesterol and apoB levels. Compared to non-smokers, with $\mathrm{HR}$ set at 1.00, in men who smoked, E3/E3 men had a $\mathrm{HR}=1.68$ (1.01-2.83); $\mathrm{E} 2+\mathrm{HR}=1.18(0.46-3.03)$ and in $\mathrm{E} 4+\mathrm{HR}=3.17$ $(1.82-5.51)$ with significant genotype: smoking interaction on risk $(p=0.007)$. The power of gene: environment interaction is highlighted by the Framingham Offspring Study, where in previous analysis the association of APOE and CVD risk had been examined. After adjustment for non-lipid risk factors including smoking, in the men the E2 [OR $1.79(1.15,2.77)]$ and E4 [(OR $1.63(1.13,2.34)]$ alleles showed increased risk compared to E3/E3 men. After reanalysis, testing for APOE: smoking interactions, there was no genotype effect in non-smokers but compared to this group E3/E3 smokers had a $\mathrm{HR}=1.69(1.15-3.2)$ due to the effect on smoking while E4+ smokers had a HR $=3.81(2.49,5.84)$ with a significant interaction between daily cigarette consumption and APOE genotype on risk $(\mathrm{p}=0.03)$. In the Whitehall Study II of UK Civil Servants, smoking prevalence was $17.8 \%$ in the men who had had a CHD event compared to $42 \%$ and 55\% in NPHSII and FOS, respectively. In the absence of a strong environmental challenge there was no E4 effect on risk and no APOE: smoking interaction on risk. The most likely mechanism to explain the E4: smoking interaction appears to be through a direct effect on LDL oxidation.
Conclusion: These studies support the context-dependency of the $\mathrm{E} 4$ risk-effect, but when smoking incidence is low this reduces the ability to examine a smoking: genotype interaction.

\author{
A7 \\ Genetic Variation, Omega-3 Fatty Acids and \\ Heart Disease \\ J.M. Ordovas \\ USDA-HNRCA at Tufts Univ. Boston, Mass., USA
}

Changes in diet are likely to reduce cardiovascular disease, but after decades of active research and heated discussion the question still remains: what is the optimal diet to achieve this elusive goal? Is a low fat, as traditionally recommended by multiple medical societies? Or a high monounsaturated fat as predicated by the Mediterranean diet? Perhaps a high polyunsaturated fat based on the cholesterol lowering effects? The right answer may be all of the above but not for everybody. A well-known phenomenon in nutrition research and practice is the dramatic variability in interindividual response to any type of dietary intervention. There are many other factors influencing response, and they include, among many others, age, sex, physical activity, alcohol, and smoking as well as genetic factors that will help to identify vulnerable populations/individuals that will be benefit from a variety of more personalized and mechanistic based dietary recommendations. This potential could and needs to be developed within the context of nutritional genomics that in conjunction with systems biology may provide the tools to achieve the holy grail of dietary prevention and therapy of cardiovascular diseases. This approach will break with the traditional public health approach of "one size fits all." The current evidence based on nutrigenetics has begun to identify subgroups of individuals who benefit more from a low fat diet, whereas others appear to benefit more from a high monounsaturated or polyunsaturated fat (PUFA) diets. Of interest is the increasing evidence showing that when it comes to cardiovascular health, n-6 and n-3 families of PUFAs interact very differently with genetic variants to modulate cardiovascular risk factors. Thus, while some subgroups of individuals may be at higher risk from high consumption of PUFA n- 6 [i.e., carriers of the minor allele at the APOA5$1131 \mathrm{~T}>\mathrm{C}$ single nucleotide polymorphism], others may greatly benefit from increased consumption of PUFA n-3 (i.e., carriers of the APOA5-1131C or the A allele at the IL1beta $6054 \mathrm{G}>\mathrm{A}$ SNP). The continuous progress in Nutrigenomics will allow us to identify those persons for whom diet plays no major role in their risk of CVD as well as those persons who may benefit from specific gene-based dietary advice.
J Nutrigenet Nutrigenomics 2008;1:59-90 1st Congress of the International Society of Nutrigenetics/Nutrigenomics (ISNN) 


\section{A8}

\section{A Nutrigenomcs Approach to Define a "Lifestyle Algorithm" to Be Used in Cardiovascular Disease Prevention, Diagnosis and Therapy}

\section{Arbo 1, H.-R. Brattbakk', F. Lindberg', B. Kulseng ${ }^{1,2}$, M. Langaas ${ }^{1}$, B. Johansen ${ }^{1}$ \\ ${ }^{1}$ Norwegian university of science and technology, Trondheim, ${ }^{2}$ Regional centre for obesity treatment at St. Olavs university hospital, Trondheim, ${ }^{3}$ Dr. Lindbergs clinic- Weight in balance, Oslo, Norway}

Background and Goals: The aim is to study how diet predisposes for, and influences, lifestyle disease development and its consequences in cardiovascular artery disease (CAD) development. We focus on differential gene expression analysis in response to changes of diet macronutrient composition between a typical Western diet and a so called "low carbohydrate/high protein" or balanced diet. We aim at proposing new, scientifically substantiated hypotheses on mechanisms underlying development of CAD by identifying novel genes involved in disease progression that can be exploited as indicators in disease prevention, diagnosis and therapy. The project will lead to further development and integration of several technological methods including microarray analysis, bioinformatics and computational biology, all central aspects of nutrigenomics and systems biology.

Methods: The study to be accomplished is based on a performed pilot time course study on healthy obese male subjects undergoing a normal caloric diet intervention, eating normal food with specified macronutrient composition for four weeks, with sampling at time points $0,1,2,7,14$ and 28 days. In the pilot study, transcriptional profiling was performed on three biological replicates to identify optimal length of diet intervention for stabilization of gene expression to occur. Our coming study will be carried out on healthy Norwegian home guard soldiers, who in a cross-over design will feed on a powder-based diet only, for two ten-day periods with a normal food washout period in between. Blood samples for transcriptome and other biomarker analysis will be collected at several time points during the study. Transcriptional profiling will be carried out using about 40 biological replicates, alongside metabolic and protein analysis.

Results and Conclusion: The pilot study gave a list of best ranked genes indicating that more genes known to be related to immunity and inflammation are transcriptionally downregulated than are upregulated even from the first day after dietary change. The preliminary results have strengthen our believe in significant findings in our coming main study.
A9

\section{Nutriepigenomics of Metabolic Syndrome}

\author{
O. Šeda, L. Kazdová, V. Křen, D. Křenová, J. Tremblay, \\ P. Hamet, L. Šedová \\ Charles University, Prague; IKEM Prague, Czech Republic; \\ Research Centre CHUM, Montreal, Quebec, Canada
}

The role of fetal and early life environment in the determination of disease in adult life, including such prevalent conditions as hypertension, insulin resistance and dyslipidemia, is supported by a growing body of evidence. We assessed the potential of high-sucrose diet (HSD) to induce genotype-specific developmental plasticity responses in offspring of HSD-fed rat dams of two inbred models of metabolic syndrome, polydactylous rat (PD) and congenic BN.SHR4 rat (carrying defective allele of Cd36 of SHR origin).

Methods: Rat dams were fed either HSD or standard diet (STD) for 1 week before breeding, through pregnancy, birth, till weaning of the offspring. The 5-month-old male offspring were further divided into 2 groups that were fed either HSD or STD for 2 weeks. The metabolic (incl. glucose tolerance, insulin sensitivity of adipose tissue and muscle, lipid deposition in liver and muscle), morphometric and transcriptomic (in liver by Affymetrix Rat Exon 1.0 ST Array) profiles were assessed in all 8 strain*maternal diet*offspring diet combinations. Data were analyzed by general linear model ANOVA.

Results: We have found 3 patterns of differences in the profiles of the offspring: 1) metabolic programming effect regardless of genetic background (increase in insulin-induced glycogenesis in skeletal muscle); 2) genetic difference between strains with no effect of programming (e.g. amount of visceral fat higher in PD, cholesterol concentration in liver higher in BN.SHR4), and 3) interaction between genetic background and the metabolic programming (increase in plasma free fatty acids and cholesterol in BN.SHR4 offspring of HSD-fed mothers and decrease of both parameters in PD). Transcriptome analysis revealed distinct pathways/clusters between matched and mismatched maternal *offspring diet combinations as well as between strains for equivalent diet settings. PD was generally more sensitive to programming effect of HSD, showing significantly higher numbers of differentially regulated genes in offspring of HSD vs. STD-fed dams compared to BN.SHR4.

Conclusion: Our results support the fundamental role of maternal diet during pregnancy and lactation for metabolic setting of the offspring, as shown in genetically identical rats. Several distinct results including different gene expression responses found in the BN.SHR4 show the importance of genetic background in metabolic programming. 


\section{Session II: Gene-Nutrient Interactions and Hypertension}

\section{A10 \\ Dietary Manipulation, Pharmacogenetics, and Genetic Interactions Reveal Defective Genetic Control of Blood Pressure}

S.C. Hunt

University of Utah, Salt Lake City, Utah, USA

A number of genes have been consistently related to elevated blood pressure and hypertension, but the observed effects of these genes are small and hard to replicate in all studies. These common genes have almost always been related to renal electrolyte handling, similar to mechanisms of the rarer monogenic hypertension disorders. Several large studies now have the power to detect hypertension genes with smaller effect sizes and to assess interactions with diet and other environmental risk factors for hypertension. Intervention studies appear to magnify the baseline effects of genes so that they are more easily detected. In addition to genetic interactions with dietary salt on blood pressure, there appear to be important but less understood genetic interactions with dietary fat and cholesterol on blood pressure pathways. Multiple interventions including less dietary salt, increased dietary potassium, increased fruits and vegetables, low fat diets, weight loss, and drug treatment appear to help reduce blood pressure in subjects genetically susceptible to hypertension. As one would hope, it appears that those at highest genetic risk of hypertension compared to those at low risk show a greater improvement in blood pressure for interventions that target the defective genetic pathways. There remains an urgent need for the addition of dietary and pharmacologic interventions to genetic studies and vice versa, so that biological mechanisms may be uncovered represented by these statistical interactions and that additional interactions may be discovered. Knowledge arising from such studies may be used to design specific dietary, exercise, weight-loss, and drug interventions for the subset of patients who will benefit the most from that intervention.

\section{A11}

\section{Variability Genes, Blood Pressure and Coronary Heart Disease Risk}

\section{S. Humphries, F. Drenos, A. Muthumala, H. Montgomery}

Centre for Cardiovascular Genetics, British Heart

Foundation Laboratories, The Rayne Building,

Royal Free and University College London Medical School, London, UK

The concept of 'variability genes' proposed by Berg in the 1980's is based on the idea that some genotypes may pre-dispose to higher risk of CHD by influencing the extent of change in a CHD risk factor, within an individual, over time. Individuals whose mean level of a risk factor is genetically determined to be low, but who have the "variability' genotype may show higher risk when they cross a biologically critical threshold. By contrast, those who have genetically determined higher mean levels, but whose variability is small, have a much smaller probability of crossing the threshold. We have explored this hypothesis using 3000 healthy middle-age men, followed prospectively for 15 years for CHD events, in whom base-line and 5 annual measures of CHD risk factors were available. Individuals who went on to develop definite CHD $(n=230)$ showed greater variability in both systolic and diastolic blood pressure compared to those men who did not experience a CHD event. Analysis of 89 SNPs in genes involved in CHD risk factor trait levels (lipid metabolism, coagulation, rennin angiotensin systems, etc) were examined to explore possible biologically relevant associations with the extent of within-individual variability in systolic and diastolic blood pressure. Although several SNPs showing statistically significant association were identified, because of multiple testing, these are being interpreted with caution until replication can be carried out. The relationship between the well studied $A C E I-D$ polymorphism on CHD risk in these men was examined in more detail. Overall, no genotype-CHD risk association was found, but when analysed by quartiles of systolic blood pressure, compared with II homozygotes, carriage of each additional D allele was protective in those with low SBP, but in the highest quartile (SBP $>150 \mathrm{~mm} \mathrm{Hg}$ ) conferred almost 1.5 times the risk for CHD (genotype interaction $\mathrm{p}=0.003$ ). Thus the $\mathrm{D}$ allele was protective against CHD at lower SBP but would overtake the II risk at higher SBP. In hypertension, the pro-inflammatory or pro-hypertropic properties of angiotensin II may explain this association. The $L P L$ S $447 \mathrm{X}$ polymorphism also impacts on CHD risk through interaction with hypertension and there was an additive action of the ACE and LPL polymorphisms and SBP on CHD risk. Thus in the presence of hypertension, common variation in modifier genes conferred significant risk. The identification of the genetic determinants of both SBP and of the variation in SBP, along with information on modifier genes, may give useful insights into the underlying pathological processes of CHD.
A12
Variants in Genes of Metabolic and Signaling Pathways Impacted by Lipid-Based Molecules and Their Association with Age-Related Macular Degeneration

\author{
J.P. SanGiovanni', E.Y. Chew ${ }^{1}$, A. Vora², S. Ajudua ${ }^{3}$, \\ T.E. Clemons ${ }^{4}$, A.K. Henning 4 , M. Elashoff 4 \\ ${ }^{1} \mathrm{NEI}-\mathrm{NIH}$, Bethesda, ${ }^{2}$ UMDNJ, Camden, ${ }^{3}$ Brown University, \\ Providence, ${ }^{4}$ EMMES Corp., Rockville, USA
}

Objective: To examine the association between age-related macular degeneration (AMD) and allelic variants in genes of metabolic and signaling pathways impacted by lipid-based molecules.

Methods: We applied data from 2 whole-genome case-control association studies to interrogate variants of genes from 188 healthy elderly AMD-free people and 377 people with advanced AMD. Details of the study design, outcome ascertainment, genomic profiling, and participant characteristics exist in Klein et al. (Science; 308:385. 2005) and http://www.ncbi.nlm.nih.gov/. We used curated 
gene catalogues and the Ensemble and NCBI databases to identify 7946 SNPs on our microarrays that had positional markers in regions of 1427 lipid-associated genes that also met $95 \%$ data call rate and Hardy-Weinberg Equilibrium filters. We compared allele combinations of these variants in controls to those in people with advanced AMD in statistical models adjusted for age-, sex- and known AMDsusceptibility loci; participants were phenotyped annually with a standardized protocol at a centralized reading center over a 12-year period. A P-value threshold of 0.002 for allelic association with AMD was determined from a false discovery rate analysis.

Results: Two variants in highly conserved genes on chromosome 11 yielded associations with advanced AMD at P-values $<0.00004$ $(\mathrm{Q}=0.15)$. One variant exists in the 3'UTR region of a gene associated with ceramide metabolism; the other exists in proximity (66 bp) to a coding region for the protein sequence of a key enzyme in fatty acid metabolism.

Conclusions: These novel and biologically plausible findings demonstrate an association of AMD with variants in genes coding for lipid-associated protein sequences. We are in the process of replicating findings in an independent sample. If results are replicated and supported by mechanistic studies, these loci may be reasonable targets guiding research on preventive and therapeutic interventions for AMD.

\section{Session III: Gene-Nutrient Interactions and Osteoporosis}

\section{A13 \\ Bone Mass Regulation by Leptin and Leptin Receptor Polymorphisms}

\section{S. Ferrari \\ Div. of Bone Diseases, WHO Collaborating Center for Osteoporosis Prevention, Geneva University Hospital, Geneva, Switzerland}

Leptin is an adipocyte-derived cytokine (or hormone) that regulates food intake and energy balance, and thereby fat mass and weight, by activating a hypothalamic receptor, $\mathrm{Ob}-\mathrm{Rb}$. Bone mass is positively correlated to body weight, fat mass and lean mass, and it is therefore tempting to speculate that leptin could play a role in the adaptation of bone mass to body size. Indeed leptin-deficient (ob/ob) mice are obese and have increased cancellous bone volume, despite hypogonadism and hypercortisolism. Later on, it was discovered that the low sympathetic tone in these mice allowed for a stimulation of bone formation and inhibition of bone resorption, -leading to the high bone mass phenotype-, indicating that leptin-stimulated beta2-adrenergic signaling from the hypothalamus normally increases bone turnover and causes cancellous bone loss. In contrast, peripheral leptin has a direct anabolic effect on cortical bone mass in rodents. Thereby increasing leptin levels in response to food intake and fat mass accumulation may play a dual role on the skeleton: it promotes cortical bone growth to allow it carrying heavier loads (weight), while it reduces cancellous bone which serves as a main calcium store. Subsequently, a number of studies have attempted to associate leptin receptor gene (LEPR) polymorphisms, in particular a Gln223Arg substitution that apparently decreases the $\mathrm{Ob}-\mathrm{Rb}$ response to leptin, with body mass index (BMI) and BMD. We investigated the association of the Gln223Arg polymorphism with bone mineral content (BMC) and BMD measured at two-year interval in 222 healthy Caucasian boys. Gln223Arg was associated with height and BMC in growing boys, thus supporting the hypothesis that the leptin system contributes to bone mass acquisition in humans. The influence of LEPR genotypes on the skeleton, however, was markedly dependent on bone area, weight and physical activity, in that most of the associations were lost after adjusting BMC for these parameters.

From these observations we conclude that genetic variation in the leptin system could contribute to the covariance of body size and bone mass.

A healthy diet and lifestyle have an important role to play in delaying onset or prevention of many common complex conditions, such as osteoporosis, type 2 diabetes and cardiovascular diseases. Nutrigenetics and nutrigenomics have the potential to bear a significant impact on health and wellness. Several studies demonstrated that, once diet and lifestyle advice has become personalized to the patient, compliance with healthy living programs improves.

To achieve the promise of nutrigenetics it will be necessary to establish its use as a routine tool in health prevention and there are several barriers to overcome for this to happen. eTEN is a European Community program providing funds to help make e-services available throughout the European Union. In addition, it enabled the creation of a consortium, EUROGENE, which has the scope of delivering nutrigenetic services to individuals, either directly or via health care clinics.

The 18-month project will involve developing e-services to enable the deployment of current (the Sciona MyCellf program) and future nutrigenetic-based profiles in pilot clinics situated in Germany, Italy, Greece and Spain. Electronic systems will be applied to localize (cultural, regulatory, language, etc.), simplify and streamline the process, enabling online selection of nutrigenetic tests and secure encrypted delivery of personalized advice. System development will also provide seamless integration with clinical records, allowing secure 
capture of patient data and monitoring of patient progress with updated personalized advice delivered upon request.

An important part of the project will be development of a clear business plan plus comprehensive market analysis and validation of the service. The final goal of EUROGENE will be to create a costeffective service through the pilot sites that can be rapidly and easily scaled to be applied to preventative healthcare clinics throughout Europe.

\section{Session IV: Genetics and Obesity}

\section{A15 \\ Genetics of Obesity: The Role of Gene-Nutrient Interactions}

\section{Pérusse \\ Laval University, Quebec, Canada}

A lifestyle characterized by regular physical activity and a healthy diet is generally recommended to prevent obesity and favour weight loss in overweight and obese individuals. However, the response to dietary interventions differs considerably among individuals and there is increasing evidence from both human and animal studies that genetic factors play an important role in determining these differences. The objective of this presentation is to review the evidence supporting the role of gene-nutrient interactions in obesity. Results from overfeeding studies in monozygotic twins have clearly shown that the response to a caloric surplus or a caloric deficit was strongly influenced by the genotype of the individual. Several candidate gene polymorphisms have been associated with response to weight loss interventions, including the PPARG Pro12Ala, the ADRB3 Tr64Arg and the FABP2 Ala54Thr polymorphisms, to name those with the stongest evidence. Gene expression profiling by microarray represents another approach that can be used for finding new genes modulating body weight responses to diet. The results from recent studies which applied this technique to study changes in adipose tissue gene expression occurring with caloric restriction and weight loss will be reviewed. As our understanding of gene-nutrient interactions in obesity improves, it will become possible to provide individuals with dietary guidance tailored to their genotype, which could improve our capacity to better prevent and treat obesity.
A16

\section{Anti-Inflammatory Diet: Search for Anti-Inflammatory Phenotype}

\section{Dimitrov}

Nutrigenomics Center Varna, Medical University Varna, Varna, Bulgaria

According to the present paradigms, a pro-inflammatory phenotype seems to contribute to the risk of developing atherosclerosis and hypertension (Ross, 1999; Libby, 2006), obesity and type 2 diabetes (Fain, 2006), and the metabolic syndrome (Shimomura et al., 1996, 2006). In the same vein, ageing involves a complex rearrangement of cytokine pattern toward pro-inflammatory status, a phenomenon called inflamm-ageing (Franceschi et al, 2001; Grimaldi et al., 2006). Because adipose tissue is a potent source of pro- and anti-inflammatory adipokines, it is logically to search for adipokine contribution to ageing and life expectancy.

n-3 LC-PUFA may act as endogenous ligands for the peroxisome proliferator-activator receptors (PPARs) $\alpha, \delta$ and $\gamma$, which have recently been recognised for their anti-inflammatory actions in adipocytes and macrophages. Treatment with n-3 LC-PUFA augments circulating adiponectin levels via a PPAR $\gamma$-dependent mechanism. Given that adiponectin is known to exert anti-inflammatory effects and enhance insulin sensitivity, it is conceivable that n-3 LC-PUFA could impede the adipose tissue switch to an inflammatory gene expression profile in response to obesity via a PPAR $\gamma$ - and adiponectindependent mechanism.

"Adiponutripharmacology" connotes the adipotargeting studies aimed at drug discovery. The following major adiponutripharmacological targets could be defined: (i) nuclear transcription factors, especially peroxisome proliferator-activated receptors and sterol regulatory element-binding protein-1, (ii) adipokines as products of intracellular secretory pathways, including endoplasmic reticulum stress and the unfolded protein response, Golgi complex, microtubules, and various exocytosis-mediated molecular complexes, (iii) adipokines as signaling molecules, (iv) insulin downstream components controlling trafficking of glucose transporter type 4-containing vesicles, (v) uncoupling proteins, including mitochondrial biogenesis, (vi) steroidogenesis mediated by adipofibroblasts, (vii) metabolic pathways of triacyglycerol and fatty acids, including lipid droplet-associated proteins, such as perilipin, adipophilin and caveolin-1, and (viii) adipose-derived stem cells.

\section{A17 \\ Predictive Genomics for Determining Genetic Predisposition to Obesity}

\section{Kambouris}

Yale University School of Medicine, New Haven, CT, USA; Geno-Type Biotechnology, Athens - Greece

Obesity is a multi-factorial polygenic disease attributable to dietary and behavioral trends acting on an individual's genetic makeup to determine traits such as body mass, adipogenesis, adipose tissue accumulation \& distribution, energy balance regulation \& utilization. 
Obesity is associated with considerable morbidity and mortality through its association with the metabolic syndrome, type 2 diabetes mellitus, heart disease, hypertension, stroke and cancer. More than 300 genes, markers and chromosomal regions have been associated or linked with obesity each convening to the relative risk for disease development.

Fifteen Single Nucleotide Polymorphisms [SNPs] in 13 different genes [ACDC, ADRB2, ADRB3, AGRP, CAPN10, FTO, GNB3, INSIG2, IL1B, IL6R, MCHR1, NPY, PPAR $\gamma$ ] were selected for the establishment of predictive genomic profiles that would determine increased genetic predisposition to obesity. Selection criteria were for the SNPs to be relevant to obesity, prevalent to the population, their expression modifiable and the modification impact measurable. The application of comprehensive high throughput profiling technologies is essential for simultaneous analyses of the multiple SNPs. Creative statistical meta-analyses are required for determination of increased predisposition as compared to the general population risk.

Determining genetic predisposition by analyzing the growing number of genes \& polymorphisms implicated in obesity and processes that contribute to the pathogenesis of obesity helps guide successful interventions for obesity control and treatments, both pharmacological and nutritional. Also it can offer improved understanding of the different "types" of obesity that not only permits the development of potential therapies, but also proposes novel and often unexpected directions in deciphering obesity.

\section{A18}

\section{ADIPOQ Gene tagSNP Associations with Serum Adiponectin in Normal Women and Tests of Promoter Activity}

\author{
T. Kyriakou' ${ }^{1}$, L.J. Collins' ${ }^{1}$, X. Wang ${ }^{2}$, H. Snieder ${ }^{2,3,4}$, \\ D.J. Hart', T.D. Spector ${ }^{4}$, S.D. O'De// \\ ${ }^{1}$ Nutritional Sciences Division, King's College London, UK, \\ 2Department of Pediatrics, Medical College of Georgia, \\ Augusta, GA, USA, ${ }^{3}$ Department of Epidemiology, \\ University Medical Center Groningen, The Netherlands, \\ ${ }^{4}$ Twin Research and Genetic Epidemiology Unit, King's \\ College London, UK
}

Adiponectin, the major adipocyte secretory protein, is one of several adipokines with roles in insulin sensitivity. It is a potent insulin sensitizer in muscle and liver, regulating energy homeostasis and glucose tolerance and hypoadiponectinemia is a general feature of metabolic syndrome traits. Adiponectin levels have a strong genetic component, with heritability estimated between 30 and $50 \%$. Adiponectin is the product of the highly polymorphic ADIPOQ gene. We investigated tagging SNPs covering the ADIPOQ gene in two independent samples of healthy Caucasian females: the Chingford Study ( $\mathrm{n}=808$, mean age 62.8 \pm 5.9 years) and Twins UK $(\mathrm{n}=2718$, mean age $47.4 \pm 12.6$ years). We selected a set of 8 tagSNPs representing all considered common variants in ADIPOQ and tested their effect, individually and as haplotypes on serum adiponectin levels, anthropometry, body fat and insulin resistance measures in two independent samples of healthy Caucasian females: the Chingford Study $(\mathrm{n}=808$, mean age 62.8 \pm 5.9 years $)$ and Twins UK $(\mathrm{n}=2718$, mean age $47.4 \pm 12.6$ years). In the Chingford cohort, tSNPs rs17300539
(-11391 G/A), rs182052 (-10068 G/A), rs16861209 (-7734 C/A), rs1501299 (+276 G/T) and rs1063537 $(+3228 \mathrm{C} / \mathrm{T})$ were significantly associated with fasting serum adiponectin levels (Ps $=0.0001$ to 0.014), explaining between 1.0 and $1.7 \%$ of the variance. Associations with all except rs 1063537 were replicated in the Twins UK cohort ( $\mathrm{Ps}=3.19 \times 10-9$ to 0.006$)$, explaining between 0.93 and $1.88 \%$ of the variance. In addition rs 16861209 was associated with BMI, weight, total fat mass, $\%$ fat, central fat mass and waist circumference ( $\mathrm{Ps}=0.003$ to 0.021 ). In the Chingford cohort, we identified two haplotypes associated with elevated serum adiponectin $(\mathrm{P}=0.0005)$ explaining $2.85 \%$ of adiponectin variance. In the Twins UK cohort a different haplotype accounted for $1.66 \%$ of the variance in serum adiponectin (overall $\mathrm{P}=5.83 \times 10^{-7}$ ). In order to investigate potential functional effects of SNP $-11391 \mathrm{G} / \mathrm{A}$, we cloned $1.2 \mathrm{~kb}$ of the ADIPOQ promoter region, which included SNPs - $11391 \mathrm{G} / \mathrm{A}$ and $-11377 \mathrm{C} / \mathrm{G}$ (rs266729), in a luciferase reporter plasmid. The four possible haplotype promoter constructs were transfected in differentiated 3T3-L1 adipocytes. No consistent significant differences in promoter activity with respect to $-11391 \mathrm{G} / \mathrm{A}-11377 \mathrm{C} / \mathrm{G}$ haplotype were observed. At present, causative effects for either SNP remain to be established.

\section{A19 \\ Association between Glutamate Decarboxylase 2 (GAD2) and Binge Eating in Obese Children: Results from the GENDAI Study \\ M. Tzirkalli', N.V. Vidra' ${ }^{1}$, A.-E. Farmaki', I. Hatzopoulou', E. Louizou', S. Sakka², E. Eustathiou², G. Kapravellou', E. Evaggelidaki ${ }^{1}$, C. Papoutsakis ${ }^{1}$, M. Yannakoulia ${ }^{1}$, G.V. Dedoussis ${ }^{1}$ \\ ${ }^{1}$ Harokopio University, ${ }^{2}$ Aghia Sofia Children's Hospital, Athens, Greece}

There is limited evidence on the role of genetic and environmental factors on the etiology of childhood obesity, a major health problem worldwide. Recently, polymorphisms in the Glutamic Acid Decarboxylase 2 Gene (GAD2) and specifically the functional $-243 \mathrm{~A}>\mathrm{G}$ polymorphism in the 5 promoter region has been associated with adult morbid obesity and childhood obesity. The Gene -Diet Attica Investigation on childhood obesity (GENDAI) is a schoolbased cross-sectional study. It evaluates the contributions and pivotal interactions of genetic, dietary and physical activity variables on children's overweight. Anthropometric, clinical genetic, socio-demographic, other lifestyle characteristics were collected from participating children. A full dietary assessment was obtained including a questionnaire on meal patterns and behaviors related to the act of eating, assessing among others binge eating behavior. Potential associations between GAD2 polymorphism and binge eating were evaluated in a subcohort of 743 children. No association was found between GAD2 $(-243 \mathrm{~A}>\mathrm{G})$ and obesity status (normal weight, overweight and obesity) in children. With regards to binge eating, no association was found between GAD2 and binge eating in normal weight children. In overweight/obese children, we observed that in obese/overweight carriers a higher percentage of AA reported binge eating phenotype compared to $\mathrm{AG} / \mathrm{GG}$ subjects (18.6\% vs. $9.9 \%$, 
$p=0.049)$. When the two sexes were examined separately, this association was found only in overweight/obese boys $(p=0.049)$ but not in overweight/obese girls $(p=0.220)$. These preliminary data indicate that GAD2 may play a role in the complex mechanisms underlying energy balance and food intake in overweight children.

\section{Session V: Genetics of Cancer}

\section{A20}

\section{Gene-Alcohol Interactions and Cancers}

M. de Lorgeril

PRETA-TIMCE Coeur et Nutrition, CNRS UMR 5525 et Faculté de Médecine de Grenoble, La Tronche-Grenoble, France

Relationships between alcohol and most cancers remain confusing.

Presence of gene-environment interactions has been suggested.

Research in gene-alcohol interactions applied to cancers is very complex due to difficulties surrounding the definition of phenotypes, environment and genotypes, as well as in estimating the influence of social context.

Likewise, the definition of alcohol consumption is also complex given that apart from the amount of alcohol consumed, the type of drink, the frequency of consumption and the associated dietary habits for instance, may be important.

No less difficult is the definition of genotype as there are many candidate genes involved including not only those relevant for each phenotype (each specific cancer) studied, but also those related with alcohol metabolism as well as those related to alcohol intake.

At least three levels of interactions have been identified: 1- geneenvironment interactions in determining alcohol consumption; 2gene-environment interactions in determining alcohol metabolism; 3 - gene-environment interactions in determining the effects of common polymorphisms on specific cancers.

The way by which these interactions are assessed depends on the study design, the variables measured and the methods of analysis.

\section{A21}

\section{Frontiers in Nutrigenetics and Nutrigenomics at the National Cancer Institute (NCI)}

\author{
J. Milner \\ Nutritional Sciences Research Group, Divison of Cancer \\ Prevention; National Cancer Institute, National Institutes \\ of Health, Rockville, Md., USA
}

It is increasingly apparent that no ideal diet exists for everyone and that nobody has a desire to eat the same diet. Evidence from both preclinical and clinical studies points to the wide variation in response to food components as modifiers of cancer risk and tumor behavior. These inconsistencies likely reflect the multi-factorial nature of signals that determine phenotypic expression and the specificity and temporal relationships existing among dietary constituents as modifiers of molecular events. The identification and elucidation of molecular sites and the variation in activity around these sites is critical for identifying those who will benefit or be placed at cancer risk. Thus a better understanding of which cancer related process are modified is fundamental to understanding the relationship between eating behaviors and cancer. Evidence already exists that limitations in specific nutrients can increase the chances of developing cancer as well as other chronic diseases, especially when specific genetic polymorphisms are present. However, inconsistencies are also in the literature about the relationship of specific polymorphisms, again likely reflecting multiple nutrient-nutrient interrelationships and gene-gene interactions are involved in establishing cancer risk and tumor behavior. Expanding knowledge about the physiological consequences of nutrigenomics- nutrigenetic (genetic profiles that modulate the response to food components), nutritional transcriptomics (influence of food components on gene expression profiles), and nutritional epigenomics (influence of food components on DNA methylation and other epigenetic events and visa versa)-will help identify appropriate dietary preemption approaches. Adding proteomic (biological fluid and cellular profiles of proteins) and metabolomic (small molecular weight compounds in fluids and cells) measurements will also help identify responders from non-responders. This presentation will focus on concepts and funding opportunities available at the NCI for promoting a greater understanding of nutrigenetics and nutrigenomics. Undeniably more attention needs to be given to three types of biomarkers: those reflecting exposures, biological effects and susceptibility. While the challenges to unraveling the relationships between diet and cancer are enormous, so are the societal and health benefits that will occur because of these discoveries. 


\section{A22 \\ Genetic Variation, Omega-6 Fatty Acids and Prostate}

\section{Hughes-Fulford}

University of California, San Francisco and VA Medical

Center, San Francisco, Calif. USA

Objectives: The relationship between inflammation and cancer was first reported by Virchow in 1863; today, the causal relationship between inflammation and cancer is widely accepted. However many of the molecular and cellular mechanisms mediating this relationship remain unresolved. This study was designed to define dietary factors that may regulate inflammation.

Methods: In this sutdy we examined the gene expression of prostate cancer cells using gene array technology and verified data with real-time RTPCR. We further examined protein induction using Western blots.

Results: Regulation of genetic expression of cancer has shown that cox-2 and inflammatory molecules are up-regulated. It is known that non-steroidal anti-inflammatory drugs (NSAIDs) reduce inflammation as well as incidence of cancer. Our laboratory has found that omega-6 FAs play a key regulatory role in inflammation which is triggered by chemokines. Detailed recent analysis from our laboratory have shown that omega-6 FAs dramatically induce gene expression of chemokines and cytokines. We have found that increased intake of omega-6 FA causes dramatic induction of bcl2, gmcsf, il-6, icam, il-8, junb, tnfa,cox-2, cxcl1, NFkb, ppar-elta and ppar-gamma. We have explored the signal transduction pathway and found that NFkB plays a major role in the regulation of these genes.

Conclusions: These results suggest that a high intake of omega-6 fatty acids can cause increased inflammation which may in turn promote cancer growth.

\section{A23 \\ Apolipoprotein E (Apo E) Genotypes, Alcohol Consumption and Risk of Sporadic Distal Colorectal Adenomas \\ P.N. Mitrou" ${ }^{1}$, M.A. Watson ${ }^{2}$, C. Cardwel/ ${ }^{3}$, C.P. Macklin 4 , T. Cecill, D.T. Bishop ${ }^{4}$, J. Primrose ${ }^{5}$, W.S. Atkin ${ }^{3}$, \\ S.A. Bingham ${ }^{1}$; Dunn Human Nutrition Unit, MRC ${ }^{1}$ \\ ${ }^{1}$ Wellcome Trust Building, Cambridge, UK and Department of Public Health and Primary Care, Cambridge; ${ }^{2}$ Dorset County Hospital, Dorset; ${ }^{3}$ Cancer Research UK, St. Mark's Hospital Northwick Park, Harrow; ${ }^{4}$ Cancer Research UK, St. Jame's University Hospital, Leeds; ${ }^{5}$ Cancer Sciences \\ Division, University of Southampton, UK}

Objective: The Apo E-genotype related variations in cholesterol absorption and bile acid metabolism have been suggested to play a role in colorectal neoplasia. Alcohol consumption has previously been associated with a 'healthier' blood lipid profile and individuals with different Apo E allele combinations are likely to respond differently to alcohol intake. However, data on the relationship of Apo E gene polymorphism and colorectal adenoma risk is still limited.
Methods: We examined the relationship between three common alleles of Apo E $(\epsilon 2, \epsilon 3$ and $\epsilon 4)$ and risk of sporadic distal colorectal adenomas in one of the largest case-control studies of 820 polyp-free controls and 822 cases, all participants of the UK Flexible Sigmoidoscopy Screening (UKFSS) Trial. The allelic variants were examined as independent risk factors and evidence for interaction with alcohol was sought. Odds ratios (ORs) and 95\% confidence intervals (CIs) were adjusted for age, sex and study centre.

Results: Investigation of the effect of the separate Apo E alleles in this large UKFSS study revealed no overall association on adenoma risk $(\mathrm{P}>0.05)$. However the combined $\epsilon 3 / \epsilon 4$ and $\epsilon 4 / \epsilon 4$ genotypes compared to $€ 3 / \epsilon 3$ were associated with an increased risk of colorectal adenoma among individuals with high alcohol consumption (OR, was $1.70,95 \% \mathrm{CI}, 1.11-2.60)$ and the P-test for interaction was marginally statistically significant $(\mathrm{P}=0.054)$.

Conclusions: These findings suggest that the Apo E polymorphism may play a role in susceptibility of colorectal adenomas in presence of alcohol-related procarcinogens.

\section{Session VI: Genetics of Diabetes}

A24

Insulin Resistance

S. Muntoni', Sa. Muntoni ${ }^{2}$

${ }^{1}$ Centre for metabolic Diseases and Atherosclerosis, The ME.DI.CO. Association, Cagliari, ${ }^{2}$ Department of Toxicology, Unit of Oncology and Molecular Pathology, University Medical School of Cagliari, Cagliari, Italy

The great majority of cases of type 2 diabetes (DM2) are associated with insulin resistance (IR), "compensatory" hyperinsulinemia and visceral obesity. IR is a disorder in which a group of genetic factors, inactivity, diet, and obesity lead to a set of metabolic disregulatory conditions such as diabetes, hypertension, malignancies, atherosclerosis, dyslipidemia, nonalcoholic steatohepatitis, and polycystic ovarian syndrome. IR affects one of the two pathways downstream the insulin receptor: phosphatidylinositol 3-kinase (PI 3-K), through which the metabolic effects are produced; while the other pathway, mitogen-sctivated protein kinase (MAP K), through which the mitogenic, atherogenic and cancerogenic effects are produced, remains sensitive to insulin. The consequences of such a dichotomy are hypoinsulinization of the former pathway, and hyperinsulinization through "compensatory" hyperinsulinemia of the latter. The biological features of such a situation find confirmation in numerous clinical studies: exogenous insulin administered to DM2 subjects with insulin resistance and endogenous hyperinsulinemia might worsen the primary endpoints, therefore resulting in potential increases in cardiovascular and cancer events and mortality, in spite of improvement of surrogate metabolic endpoints (hyperglycemia and glycated haemoglobin).This fact is reminiscent of what happens in other fields of pharmacotherapy, such as treatment of postmenopausal women with estrogen plus progestin that results in increase of cardiovascular

J Nutrigenet Nutrigenomics 2008;1:59-90 
diseases and breast cancer; or use of cyclo-oxigenase- 2 inhibitors that double the risk of heart attaks and strokes. These results confirm that pharmacologic improvement of a risk factor does not mean automatic decrease of risk. Given this background, the best way to treat DM2 patients with insulin resistance and endogenous hyperinsulinemia is to avoid exogenous insulin (with the exception of particular conditions such as acute complications of diabetes, cases progressed to beta-cell failure, intervening diseases) and to reduce insulin resistanc with lifestyle modifications. When necessary, and not contraindicated, administration of metformin is recommended, as this was shown to improve both primary and secondary endpoints.

\section{A25 \\ Association between the Risk of Type 2 Diabetes and Variants in Genes Involved in $\beta$-Cell Function and Hepatic Gluconeogenesis in a Chinese Han Population}

Y. Wu ${ }^{1 *}, H . L i^{1 *}, R . \operatorname{Loos}^{2}, X . \operatorname{Lin}^{1}$

${ }^{1}$ Institute for Nutritional Sciences, Shanghai Institutes for Biological Sciences, Chinese Academy of Sciences and Graduate School of the Chinese Academy of Sciences, Shanghai, China, ${ }^{2} \mathrm{MRC}$ Epidemiology Unit, Institute of Metabolic Science, Addenbrooke's Hospital, Cambridge, UK

Rapid nutrition transition and its interaction with susceptible genes are key factors which lead to type 2 diabetes epidemic in Asian populations. However, it is unclear whether specific variants in the genes involving in $\beta$-cell function and liver gluconeogenesis predispose to type 2 diabetes in Chinese population. This is a case-control study, for the first time to our knowledge, to systematically investigate the distribution of variants in the candidate genes encoding key components of insulin secretion of pancreatic $\beta$ cells and hepatic gluconeogenesis, and their associations with type 2 diabetes in a large Chinese Han population consisting of 513 unrelated type 2 diabetic individuals and 1914 participants with normal fasting glucose. A total of 43 SNPs from 14 candidate genes including ABCC8, KCNJ11 (KIR6.2), GCK, TCF1, SLC2A2 (GLUT2), PPARG, PPARA, UCP2, PPARGC1A, PEPCK, G6PC, HNF4A, NR3C1 and ESRRA were examined for their associations with type 2 diabetes. After adjustment for age, sex and BMI, significant associations were observed between type 2 diabetes and PPARG P12A(rs 1801282) (odds ratio[OR] $=0.69$, $95 \%$ CI $0.49-0.96, p=0.030), \mathrm{KCNJ} 11 \mathrm{I} 337 \mathrm{~V}(\mathrm{rs} 5215)(\mathrm{OR}=1.19$, $95 \%$ CI $1.02-1.39, \mathrm{p}=0.025)$ and $\mathrm{NR} 3 \mathrm{C} 1 \mathrm{rs} 7701443(\mathrm{OR}=0.68$, $95 \%$ CI $0.48-0.95, \mathrm{p}=0.025)$ polymorphisms in the whole population, and association of KCNJ11 E23K(rs5219) (OR $=1.31,95 \% \mathrm{CI}$ $1.04-1.63, \mathrm{p}=0.021)$, PPARGC1A G482S(rs8192678) $(\mathrm{OR}=1.50$, $95 \%$ CI $1.01-2.21, \mathrm{p}=0.044)$ and $\mathrm{rs} 2946386(\mathrm{OR}=1.38,95 \% \mathrm{CI}$ $1.01-1.88, \mathrm{p}=0.046)$ with type 2 diabetes were found to be significant only in men $(n=1457)$. Among these gene variants, NR3C1 rs7701443 is a novel variant found to be associated with type 2 diabetes in Chinese Hans. In contrast, haplotype analyses revealed that TGC haplotype defined by SNP rs2425637, 2425639 and rs 1800963 in HFN4A gene was significantly associated with type 2 diabetes only in the women. The TGC haplotype carriers had a remarkably alleviated risk for type 2 diabetes when comparing with other female individuals $(\mathrm{OR}=0.792,95 \% \mathrm{CI} 0.641-0.978, \mathrm{p}=0.030)$. No significant association was observed between the variants in the other candidate genes and type 2 diabetes in our study. In conclusion, our findings suggest that variants in PPARG, KCNJ11, NR3C1 and possibly PPARGC1A may contribute to the risk of type 2 diabetes in Chinese population.

*These authors contributed equally to this work.

\section{A26 \\ The Effect of Conjugated Linoleic Acid on Gene Expression of Resistin and Adiponectin in Obese Rats Fed with a High Fat Diet}

\author{
X.-R. Zhou, C.-H. Sun, Y. Li \\ Public Health College, Harbin Medical University, Harbin, P. \\ R. China
}

Background: Conjugated linoleic acids (CLA) are a class of positional, geometric, conjugated dienoic isomers of linoleic acid. Dietary CLA supplementation results in a dramatic decrease in body fat mass in mice. However, some but not all studies in mice and humans have found that CLA promotes insulin resistance, the molecular mechanisms responsible for these effects are unclear.

Objective: We investigated the effect of CLA supplementation on insulin resistance in obese rats fed a high fat diet, and explore the molecular mechanisms.

Method: In this study, male wistar rats were randomly separated to control group, high-fat group and high fat + conjugated linoleic acid group $(0.75 \mathrm{~g} \cdot 1.50 \mathrm{~g} \cdot 3.00 \mathrm{~g} \%$ by deit weight), we observed the effect of CLA on blood glucose and insulin levels of insulin resistant rat, and using reverse transcription polymerse chain reaction (RT-PCR) technique to measure the mRNA expression level of resistin, adiponectin and activity peroxisome proliferator-activated receptor- $\gamma$ $(\operatorname{PPAR} \gamma)$ in white adipose tissue of obese rats fed with high fat diet.

Results: Our study showed that supplementation with CLA can reduce body weight gain and white fat pad weight, decrease blood glucose and plasma insulin concentrations, improve insulin resistance in obese rat, increase PPAR $\gamma$ and adiponectin gene expression in adipose tissue of obese rat. However, it was unexpected that CLA did not decrease, but increase resistin gene expression in adipose tissue of obese rat in a dose-dependant manner, which was in accordance with the increase tendency of PPAR $\gamma$ gene expression.

Conclusions: The result suggests that CLA can improve insulin resistance by activating PPAR $\gamma$ and increase adiponectin gene expression. PPAR $\gamma$ may up-regulate the gene expression of resistin, but did not support the initial report that PPAR $\gamma$ down-regulated resistin gene, and resistin's regulation mechanism in insulin resistance needs to be studied further. 


\section{Session VII: Industry and Consumers - What Is the Business Model for Personalized Nutrition and Medicine?}

\section{A27 \\ Commercial Nutrigenetic Anti-Inflammatory Products}

K. Kornman'1, J. Rogus', H. Roh-Schmidt², A. Davies², K. Randolph ${ }^{2}$

${ }^{1}$ Interleukin Genetics, Waltham, Massachusetts, ${ }^{2}$ Access Business Group, Buena Park, Calif., USA

Objective: Commercially viable nutrigenetics products must be scientifically valid, clinically useful, and profitable. As a proof-ofconcept test of scientific validity and clinical utility, we evaluated whether a specifically formulated botanical mixture reduced inflammation in individuals with genetic variations that predispose to overexpression of interleukin-1 (IL-1) and early heart disease.

Methods: Healthy adults with elevated C-reactive protein (CRP) were stratified into an IL1 positive genotype (IL1-Pos) associated with over-expression of IL-1 and early heart disease or an IL1 negative genotype (IL1-Neg). Subjects were then randomized to an experimental botanical formulation or placebo, and IL1 gene expression by peripheral blood mononuclear cells (PBMCs) and serum CRP were assayed during 12 weeks of treatment.

Results: IL-1 gene expression by stimulated PBMCs was significantly lower in the botanical group than placebo in both IL1-Pos and IL1-Neg subjects, but the botanical treatment effect was greater in IL1-Pos than IL1-Neg subjects. At 12 weeks of dosing the botanical mixture produced no mean change in serum CRP levels. However, in IL1-Pos subjects, significantly more subjects achieved a reduction in CRP with the botanical mixture than with placebo. No CRP effect was observed in the IL1-Neg subjects.

Conclusion: This study represents one of a few prospective clinical trials in which genetic variations were shown to differentially influence nutrient effects on outcomes. The role of similar studies in the development of commerically viable nutrigenetics products will be discussed.

\section{A28 \\ The Columbus Concept: A Business Model for Personalized Nutrition and Medicine}

\section{F. de Meester}

Columbus Institute SA, Waterloo, Belgium

According to the Columbus Concept, the ideal protection against the development of modern chronic diseases appears to reside in the selection of a diet that promotes a 1:1 ratio between $\omega 6$ and $\omega 3$ PUFAs and/or a 1:3 ratio between $\omega 6$ and $\omega 3$ HUFAs in circulating blood total lipids. These ratios are readily accessible through selecting animal foods that are equally balanced $(\omega 6: \omega 3$ PUFAs $=1: 1)$, and/or vegetable oils and fats that exhibit a 1:3 ratio between $\omega 6$ and $\omega 3$ EFAs. Fish and fish oils can alternatively be used in modern diets rich in $\omega 6$ PUFAs to approach those ideal ratios in diet and blood lipids. This is the "wild-diet hypothesis". Provided it can be field tested, validated and implemented at large, one may then consider personalizing nutrition and medicine to genetically-encoded and duly identified low and high respondents to certain dietary ingredients and other environmental factors. Cholesterol is here an ideal vector of further development thanks to the large amount of valuable information available in the scientific literature that relates its blood concentration and distribution to the inception and progression of modern chronic diseases.

In a first step, two subpopulations were identified, ie (1) the elderly and (2) the apoE4 genotype.

For the elderly, population studies in the oldest olds have identified a positive correlation between blood serum total cholesterol and longevity, with no influence whatsoever on cardiovascular mortality. It appears that this subpopulation would benefit from a meat-, eggand dairy-based wild-type diet rich in cholesterol and saturated fats (animal foods) since high blood cholesterol provides extra protection against infectious diseases and cancers.

For the apoE4 genotype that accounts for near $10 \%$ of the Caucasian group of individuals, population studies tend to show a positive correlation between dietary cholesterol, blood cholesterol, and modern chronic diseases. Here, there would seem to be a health advantage at selecting low cholesterol and low saturated fat alternative staple foods if they were available, even under the wild-type dietary standard.

A29

An Industry Perspective on Nutrigenomics

L.B. Fay

Nestlé Research Center, Nestec Ltd, Vers-chez-les-Blanc, Lausanne, Switzerland

Nutritional genomics (nutrigenomics and nutrigenetics) aims at deciphering the interactions between nutrition and the human genome. Nutrigenomics consider the relationship between nutrients and gene expression whereas nutrigenetics addresses the inverse relationship and investigates the effects of individual genetic variation on response to diet. High throughput genomics technologies (transcriptomics, proteomics, metabolomics, bioinformatics) are at the core of nutrigenomics. They are used to look for specific mRNA, proteins, or metabolites that, in healthy subjects, can diagnose markers to predict or measure subject response to a changing environment, to a specific diet, or to certain drug treatments in case of diseased subjects.

Within the food industry, nutrigenomics was first adopted by plant biotechnologists to influence plant biosynthetic pathways for improving human health. Today, for agricultural purposes, nutrigenomics is used to improve crops and livestock through a better understanding of their growth and feeding conditions in order to improve their health and maximise their yield. 
In human nutritional research, functional genomics is very popular. Modern nutritional research focuses on health promotion and disease prevention, on protection against toxicity and stress, and on performance improvement. The concept of developing nutritionally enhanced or functional food requires: (1) the understanding of the mechanisms of prevention and protection; (2) the identification of the biologically active molecules, and (3) the demonstrated efficacy of these molecules. The mid-term objective of nutrigenomics is integrating genomics (gene analysis), transcriptomics (gene expression analysis), proteomics (global protein analysis) and metabolomics (metabolite profiling) to define a 'healthy' phenotype. The long-term deliverability of nutrigenomics is personalized nutrition for maintenance of individual health and prevention of disease.

Last but not least, food safety also benefits from functional genomics, in particular, from genome sequencing. Indeed, genome sequences are now available for many of the microorganisms that cause food-borne diseases. DNA microarrays and proteomics enable the rapid detection and identification of those micro-organisms and allow better understanding of their ability to grow.

\section{A30 \\ Nutrigenetics \& New Market: Customizing Health Care}

\section{C.O. Cale}

Ibergene - Inovação e Serviços em Genética, S.A.; Ibergene - Innovation and Services in Genetics, Corp., Lisbon, Portugal

The understanding of the cellular and molecular mechanisms of the Human Body provides us a vision of what genomics can contribute to the field of nutrition: the ability to develop nutritional recommendations and nutritional products specifically targeted for an individual, given his genotype - that is, personalized nutrition. Since individuals genetic makeup influences his or her response to dietand growing scientific evidence suggests that diet can in turn influence gene expression patterns - a clear understanding of gene-diet interactions is an essential step in achieving this kind of personalized nutrition.

Pharmaceutical and food industries are becoming more aligned in their approach to the consumer's health concerning disease prevention and personalized nutrition. Ibergene as an innovative Portuguese Biotech Company, jointly with one of its stockholders - Portuguese Pharmaceutical Group (Iberfar) -,is committed to Nutrigenetics/ Nutrigenomics. At the moment Ibergene is leading the Portuguese market concerning the customization of personal care based on an individual's genetic profile, with a primary focus on preventive health care.

The emergent nutrigenomics industry - a market that includes both industry and consumer channels - businesses including genetic testing companies and personalized product manufacturers will have to strengthen established capacity, built on old connections, and forge new partnerships, in order to fully satisfy the new sophisticated consumers. The best diagnostic companies must be able to provide a total solution to their customers, which are taking, each day, a more proactive approach in order to manage their health and to prevent the onset of diet-related diseases, such as diabetes, cardiovascular and bone and joint diseases. This new sophisticated consumers will drive this new market.

\section{A31 \\ A Case in Commercial Applications of Nutrigenetics}

\section{B.S. Savas \\ ITT - Advanced Medical Technologies, Ankara, Turkey}

The fourth phase of the epidemiological and demographic transition has brought populations to a lower fertility status with extended life expectancy. The diseases of this phase are complex diseases, which stem from mainly the complex interaction of human genome with life style factors. These diseases are serious, chronic and costly. Cardiovascular and cerebrovascular diseases, cancers, diabetes and osteoporosis are among major chronic and complex diseases, which account for approximately two third of all deaths in the world.

Currently, the best known prevention for chronic and complex diseases is adopting a healthy lifestyle. However, this is not achieved in many places of the world. An effective intervention model including lifestyle changes for prevention of these diseases is urgently needed.

ITT - Advanced Medical Technologies is a biotechnology company (SME) established in Turkey. ITT aims to transform scientific developments in the area of biotechnology, especially genetics and genomics, into products and services that improve human health, quality of life and performance, and extend life span.

Gentest $^{\circledR}$ is the main product line of ITT on personalized medicine and nutrition. The mission of the product is changing the behavior of individuals.

Gentest ${ }^{\circledR}$ products include genetic analysis that covers common polymorphisms related with above mentioned common complex diseases and a detailed lifestyle analysis. Based on the results, an optimum lifestyle plan is drawn, including personal menu plans and exchange lists, exercise plans and smoking cessation recommendations based on the individual causes of smoking.

Gentest ${ }^{\circledR}$ products are provided only by authorized physicians and dieticians who had successfully completed training course of Turkish Nutrigenetic Society. Gentest ${ }^{\circledR}$ is produced with the collaboration of three centers of ITT, established in Hacettepe University Science Park: GENAR Biotechnology and Molecular Genetics Laboratories, TOBES Center for Public Nutrition Systems and TOGEN Center for Public Health Genomics and Personalized Medicine. These centers have also other R\&D functions independent form Gentest ${ }^{\circledR}$.

Gentest $^{\mathbb{R}}$ creates awareness by informing individuals about their current lifestyle and genetic predispositions. Further, it causes an attitude change by creating a vulnerability perception. Finally, behavior change is achieved with the follow-up programme and training. 


\section{A32}

\section{Consumer Perspectives on Nutrigenomics}

\section{S. Rowe}

SR Strategy, LLC, Washington, D.C.; Tufts University and

University of Massachusetts Amherst, MA, USA

In today's environment, the consumer perspective is central to product success. This is true even with respect to products and information that are backed by a strong scientific consensus. In areas of emerging science, such as nutrigenomics, understanding of the consumer is exponentially important. Therefore a foundation of consumer research specific to nutrigenomics is essential, but can only be successfully utilized within the context of trends related to nutrition, health, and wellness. Quantitative data suggest that consumers believe that not only diet, but also genetics affect personal health. Consumers are largely unaware of the genetics/nutrition connection, although many are favorable toward the concept once it is explained to them, and are interested in learning more. Information about one's personal genetic profile as it impacts nutritional needs for a healthy lifestyle or disease risk reduction is particularly appealing to individuals who are: aware of the concept, self-confident, parents, middle-aged, earning a moderate income, less than their ideal health and/or weight, or taking prescription medications. For these "aware" consumers, it is important to recognize the constant media barrage experienced by consumers. Beyond traditional media and even the Internet, consumers are influenced by an evolving cadre of innovative media sources and channels. This rapidly advancing communications environment, in addition to rapidly evolving scientific evidence, raises and emphasizes ethical concerns for both opinion leaders and consumers regarding appropriate use of genetic information 


\section{Poster Presentations}

\section{Journal of \\ Nutrigenetics \\ Nutrigenomics}

\section{P1 \\ Comparison of Genome-Wide Microarray Data with Differentially Expressed Proteins in Colon Tissue of Interleukin-10 Gene-Deficient Mice Inoculated with Intestinal Bacteria

\author{
M.P.G. Barnett', W. Laing ${ }^{2}$, J. Cooney ${ }^{3}$, D. Barraclough², \\ M. Davy², W.C. McNabb' ${ }^{1}$ S.T. Zhu ${ }^{4}$, N.C. Roy ${ }^{1}$ \\ ${ }^{1}$ Food, Metabolism \& Microbiology, AgResearch, \\ Palmerston North, NZ; HortResearch ${ }^{2}$ Auckland and \\ ${ }^{3}$ Hamilton, NZ and ${ }^{4}$ The University of Auckland, \\ New Zealand
}

Inappropriate responses to normal intestinal bacteria are involved in the development of Inflammatory Bowel Diseases and variations in the host genome may mediate this process. The interleukin-10 genedeficient (IL10-/-) mouse has been reported to develop colon colitis, in part due to such inappropriate responses. Our aim was to characterise differences in colon cell gene and protein expression of IL10-/and $\mathrm{C} 57 \mathrm{BL} / 6 \mathrm{~J}$ (control) mice orally inoculated at 5 weeks of age with complex intestinal flora (CIF) derived from healthy control mice. At 12 weeks of age, RNA and protein were extracted from intact colon for gene (Agilent 44k mouse array) and protein profiling. Lists of differentially expressed genes were generated using linear models for microarray analysis (Bioconductor), and genes clustered using GeneSpring GX and Ingenuity Pathways Analysis (IPA) software. Protein samples were analyzed by on-line 2D-LCMS using simultaneous salt and RPC gradients on an Ettan MDLC coupled to a Finnigan LTQ mass spectrometer fitted with a nanospray interface. Full-scan mass spectra were collected in profile mode and MS/MS spectra in centroid mode using a data-dependant top3 method with dynamic exclusion enabled. Peptide detection, intensity map comparison and quantitation were done on the full-scan precursor mass spectra using DeCyder MS Differential Analysis Software. Differentially expressed peptides were identified using the MS/MS spectra in TurboSEQUEST protein identification software. In colon of IL10-/- mice inoculated with CIF, 3475 genes were differentially expressed $(\mathrm{P}<0.05)$. Using IPA, these genes were compared to proteins differentially expressed in the same tissue (67 proteins, $\mathrm{P}<0.05$ ); genes and proteins in the glycolysis/gluconeogeneis, butanoate metabolism and valine, leucine and isoleucine degradation pathways showed differential expression in colon of CIF-inoculated IL10-/- mice compared to controls.

\section{P2 \\ Effects of Two Promoter Polymorphisms in the COX-2 and IL-6 Genes on Serum Inflammation Markers and their Modulation by the Mediterranean Diet}

\author{
D. Corella1, M. Guillén ${ }^{1}$, P. Carrasco ${ }^{1}$, C. Ortega 1 , \\ J. Salas², M. Sotos' ${ }^{1}$ J. Sorlí1, P. Guillem-Sáiz', \\ C. Burguete 1, R. Estruch ${ }^{3}$ \\ ${ }^{1}$ University of Valencia and CIBER Fisiopatología de la \\ Obesidad y Nutrición, Valencia, ${ }^{2}$ University Rovira i Virgili, \\ Reus, ${ }^{3}$ Hospital Clinic, Institut d'Investigacions \\ Biomèdiques August Pi Sunyer (IDIBAPS), Barcelona, \\ Spain
}

Background: Inflammatory processes play a relevant role in atherogenesis. Thus, high concentrations of inflammation and endothelial dysfunction markers, such as interleukin 6 (IL-6), C-reactive protein (CRP), soluble intercellular adhesion molecule 1 (ICAM-1) and vascular cell adhesion molecule-1 (VCAM-1) have been shown to predict cardiovascular disease risk. Moreover, some studies have found that the Mediterranean diet can reduce serum concentrations of inflammation markers. However, none of these studies have analyzed the influence of genetic variability in such a response.

Objective: To study the effect of the $-765 \mathrm{G}>\mathrm{C}$ polymorphism in the cycloxygenase-2 (COX-2) gene, a key regulatory enzyme in eicosanoid metabolism, and the $-174 \mathrm{G}>\mathrm{C}$ polymorphism in the IL-6 gene on serum concentrations of IL-6, CRP, ICAM-1, VCAM-1 at baseline, as well as their influence on the response to a nutritional intervention with Mediterranean diet in a high cardiovascular risk Mediterranean population.

Methods: We included 721 Caucasian subjects (314 men and 407 women) participating in the PREDIMED (PREvención con DIeta MEDiterránea) Study, which is a parallel-group, multi-center, controlled, randomized clinical trial aimed at assessing the effects of the Mediterranean Diet on the primary prevention of cardiovascular disease. Participants were randomly assigned to 1 of 3 diet groups: Mediterranean diet supplemented with virgin olive oil, Mediterranean diet supplemented with nuts, and control group. Measures were obtained at baseline and after a 3-month intervention period.

Results: At baseline, the $-765 \mathrm{G}>\mathrm{C}$ COX -2 polymorphism was consistently associated with serum IL-6 concentrations $(5.85 \pm 4.82$ in $\mathrm{GG}$ vs $4.74 \pm 4.14 \mathrm{pg} / \mathrm{mL}$ in $\mathrm{C}$ allele carriers; $\mathrm{P}=0.002$ ). There were also lower concentrations of ICAM-1 in $\mathrm{C}$ allele carriers (265.8 \pm 114.8 in GG vs $243.0 \pm 107.1 \mathrm{ng} / \mathrm{mL}$ in C carriers; $\mathrm{P}=0.018$ ). For the IL-6 polymorphism, only a significant association was found with higher ICAM-1 concentrations, and on stratifying by gender, an association with higher IL-6 in men. Following the dietary intervention, no statistically significant gene-diet interaction was found with any of the polymorphisms studied. In conclusion, although the $-765 \mathrm{G}>\mathrm{C}$ COX -2 and the $-174 \mathrm{G}>\mathrm{C}$ IL-6 polymorphisms are associated with some infammation markers, intervention with

\section{KARGER \\ Fax +41613061234 \\ E-Mail karger@karger.ch}

www.karger.com
(C) 2007 S. Karger AG, Basel

Accessible online at: www.karger.com/jnn 
Mediterranean diet reduces the concentration of these inflammation markers regardless of these polymorphisms.

P3

\section{Obesity and the T102C Polymorphism of the 2A Serotonin Receptor (5-HT2A): Association and Dietary Pattern Analysis}

I.B.M. da Cruz', C.H.A. Schwanke², I.E. da Cruz Jung ${ }^{1}$, M.I.U. da Costa ${ }^{1}$, C. Kewer ${ }^{1}$, P.A.S. do Prado Lima

${ }^{1}$ Biogenomics Lab, Departamento de Morfologia, Universidade Federal de Santa Maria, ${ }^{2}$ nnstituto de

Pesquisas Biomédicas, Pontifícia Universidade Católica do Rio Grande do Sul, Brazil

Introduction: Serotonin (5-hydroxytryptamine; 5-HT) 2A receptors contribute to the effects of 5-HT on platelet aggregation, vascular smooth muscle cell proliferation, and are reportedly involved in decreases in plasma levels of adiponectin, an adipokine, in diabetic subjects. This receptor is also one of the receptors mediating the effects of serotonin on feeding and satiety. Our team previously reported association between $\mathrm{T} 102 \mathrm{C}$ polymorphism and protein intake preference suggesting genetic influence in the eating behavior.

Objectives: To study the possible association between the T102C polymorphism and obesity as well as if this association has any influences in habitual dietary patterns.

Methodology: A case-control study was performed using a sample of 309 obese $(\mathrm{BMI}>$ or $=30, \mathrm{Ob}=125)$ and no-obese $(\mathrm{NO}=184)$ subjects older than 60 years old. They were selected from a Brazilian epidemiological study on aging and non-transmissible diseases developed in the city of Gravatai-RS. The habitual dietary pattern was assessed by a semi-quantitative food-frequency questionnaire and by 24 h-recall at monthly intervals. Details of T102C polymorphism genotyping is given in Prado-Lima et al. (Mol Psychiatry,11: 889-891, 2006).

Results: $\mathrm{Ob}$ group presented higher frequency of $\mathrm{C}$ allele than NO group $(\mathrm{OR}=1,996,95 \% \mathrm{IC}=1,142-3,488, \mathrm{p}=0.014) . \mathrm{Ob}+\mathrm{C}$ allele carriers presented higher carbohydrate and vitamin A consumption than other groups.

Conclusion: $\mathrm{T} 102 \mathrm{C}$ results suggest positive interaction between $\mathrm{T} 102 \mathrm{C}$ polymorphism to obesity and habitual dietary pattern in obese subjects. Complementary studies to confirm this association need to be performed.
P4

\section{(Nutri)Genetic Testing: A New International Opinion Survey}

\section{De Lorenzo}

Departament de Ciències Mèdiques Bàsiques, Institut de Recerca Biomèdica de Lleida - RBLLEIDA, Universitat de Lleida, Spain

The e-commerce market is growing steadily worldwide. At the same time, recent advances in the genetic diagnosis have opened a window for DTC kits ("Direct-to-Consumer" kits, typically a set of tools that are sent to the customer, with which he/she can obtain his/ her own biological sample, with the purpose of sending it per post to a laboratory for processing). Even when Nutrigenomics is a relative new research field, many companies are offering already DTC kits for personalized nutrition. It is probable that this kind of e-commerce will increase in the coming years. With this idea in mind, I developed an online survey for genetic testing. The main results are restricted to three origins: Germany, Spain and America (divided in Spanish- and English-speaking communities).

The key findings of this survey are the following: Around $80 \%$ of the public say they are at least somewhat familiar with the words "genetic testing". An overwhelming 65\% majority believes that genetic testing is a good thing. Only 5\% manifest their repulsion to the idea.

$75 \%$ of all adults say they would probably ask for a comprehensive genetic test that would indicate the likelihood that they might get several major diseases. The main reason for being tested (30\%) is to know the possible genetic diseases that they could transmit to their children, while around $20 \%$ of the people would be interested in knowing the nutritional requirements given by their genetic background.

The price mostly accepted for the DTC kits by the participants in the survey is 100 EUR (137 USD). The main factors to prefer a specific company to perform the test are company quality and post-test medical counseling (to give advice in the possible preemptive measures).

The results of this online poll establish that there is a real market for genetic and nutrigenetic testing (personalized nutrition) if the costs of these tests are not prohibitive. At the same time, is important to notice that the demand for these tests will depend heavily on the extent to which the genetic diseases can be treated or prevented. Therefore it is not only relevant in this context to find markers associated to the main nutritional diseases, but also to discover the causes of these diseases and to find an adequate and effective cure for them. 
P5

The Relationship between Adherence to the Mediterranean Diet and the Interleukin-1 (IL-1) Receptor Antagonist Gene Polymorphism in Normal Weight Obese Syndrome

\author{
L. Di Renzo ${ }^{1,2}$, A. Andreoli1 ${ }^{1}$ A. De Lorenzo ${ }^{1,2}$ \\ ${ }^{1}$ Department of Neuroscience, Division of Human \\ Nutrition; University of Tor Vergata, Rome, ${ }^{2}$ I.N.Di.M, \\ National Institute for Mediterranean Diet and \\ Nutrigenomic, Reggio Calabria, Italy
}

Interleukin-1 receptor antagonist serum concentration increases in human obesity, and it is under genetic control. We tested the hypothesis that the polymorphism in the Interleukin-1 receptor antagonist gene second intron might be associated with Normal Weight Obese syndrome (NWO), namely De Lorenzo syndrome. Despite NWO women showed a reference body weight and Body Mass Index (BMI), they showed some obesity-related abnormalities, such high Fat Mass percentage (FM\%) Their style of diet was completely different from Mediterranean diet .

The Interleukin-1 receptor antagonist single polymorfism genotype distributions and Interleukin- $1 \alpha$ and $\beta$ were evaluated in 110 Caucasian Italian women, divided in three groups: nonobese, normal weight obese and preobese-obese.

The Allele 1 frequency was not significantly different in the three groups. The Allele 3 and Allele 4 were not observed in any group. The Allele 2 frequency in normal weight obese woman (11\%) and preobese-obese $(15.3 \%)$ groups were significantly different in comparison with the nonobese group (5\%). The Allele 5 was observed exclusively in nonobese and normal weight obese subjects $(13.3 \%$ and $7 \%$, respectively). In normal weight obese women, plasma concentrations of Interleukin- $1 \alpha$ and Interleukin- $1 \beta$ were significantly higher than in nonobese.

The Allele 2 was observed in normal weight obese as well as a significant association between the increase of Interleukin-1 $\beta$ plasma amount and the Allele 2 carrier. Our findings suggest that no adherence to the Mediterranean diet results in development of inflammatory events, in particular in association with specific genetic pattern. In the present study we have examined whether the VNTR polymorphism of the IL-1Ra gene could be associated with the NWO syndrome: our data suggest that the Allele 2 might be an important high-risk genetic marker for normal weight obese syndrome and obesity related diseases.

\section{P6 \\ Comparison of the Effects of Eicosapentaenoic Acid, Vitamin E, and their Combination on Inflammatory Response in Male Basketball Players}

\author{
A. Djazayery, R. Ghiasvand, M. Jalali, S.A. Keshavarz, \\ M. Hosseini \\ School of Public Health, Tehran University of Medical \\ Sciences, Tehran, Iran
}

Introduction: Strenuous exercise is accompanied by increased oxidative stress and circulating pro-inflammatory and inflammationresponsive cytokines. The objective of this study was to investigate the effects of vitamin E and eicosapentaenoic acid (EPA) supplementation on the blood levels of pro-inflammatory cytokine TNF- $\alpha$, antiinflammatory cytokine IL-2, and the antioxidant enzyme glutathione reductase in male basketball players.

Materials and Methods: In a randomized double-blind placebo-controlled clinical trial 37 healthy, well-trained male basketball players (aged 17-35 yr) were randomized to receive daily either $2 \mathrm{~g}$ EPA (plusEPA ${ }^{\mathrm{TM}}$, Minami Nutrition, Belgium), or $400 \mathrm{mg}$ vitamin E, or a combination of the 2 , or a placebo for 6 weeks. Venous blood samples were obtained from all subjects between 5:00 and 6:00 p.m., after exercising for 2 hours, at the baseline and after intervention. Serum IL-2 and TNF- $\alpha$ were measured by Bender Medsystems kits (Vienna, Austria) using enzyme-linked immunosurbent assay. Glutathione reductase was determined by the Sauberlich method.

Results: Thirty-four subjects completed the study. As compared to the vitamin E, EPA, or placebo groups, there was a decrease (paired t-test) in the serum TNF- $\alpha$ levels $(\mathrm{p}<0.005)$ and an increase in the serum IL-2 levels in the EPA+vitaminE group $(p<0.05)$. Furthermore, the erythrocyte glutathione reductase levels significantly increased in both the EPA+vitaminE $(p=0.04)$ and vitaminE groups $(p=0.01)$.

Conclusion: This study showed that in male basketball players, 6 weeks of plusEPA ${ }^{\mathrm{TM}}+$ vitamin E supplementation increases the plasma levels of anti-inflammatory cytokine IL-2 and the antioxidant enzyme glutathione reductase, whereas it reduces pro-inflammatory TNF- $\alpha$ levels. In other words, adding plusEPA to vitamin E supplements results in desirable changes in the inflammatory response in male basketball players.

\section{P7 \\ Case Study of an Anti-Inflammatory
Ingredient Discovered via Nutrigenomic
Screening}

A. Gosslau

WellGen Inc., North Brunswick, New Jersey, USA

Effects of the black tea compound theaflavin-2 (TF-2) against inflammation were analyzed in different cell-based and animal models as well as in clinical trials by nutrigenomic screening. Experiments using colon cancer cells (Caco-2) demonstrated a downregulation of TPA-induced expression of COX-2, TNF-a, iNOS, ICAM-1, NFkB, 
and p53 as demonstrated by RT-PCR. Broader screening employing a proprietary inflammation-targeted oligo-microarray showed downregulation of COX-2, LTA4 Hydrox, TNF-a, TNF- $\alpha$ receptor, iNOS, ICAM-1, IL-1b, IL-6, IL-8, IL-10, IL-18, p53, c-Jun, and NFkB in human macrophages (U-937). Dose response and kinetics analyses of COX-2 expression by RT-PCR and invader analysis revealed strong inhibition by TF-2 after $3 \mathrm{~h}$ in Caco- 2 and HeLa cells being effective starting between 30 and $75 \mathrm{uM}$. COX-2 promoter analysis using GFP as a reporter gene suggests direct or indirect inhibitory effects of TF-2 on transcription factors such as NFkB, CREB, Sp-1, GATA-1, NF-Il-6, PEA-3, and/or TBF. Experiments employing a mouse ear edema model showed suppressive effects on edema formation which correlated to attenuation of metabolites of the COX-2 and 5-LOX pathway (e.g. PGE2 and LTB4). Gene profiling using a mouse skin model showed a downregulation of TPA-induced expression of COX-2, IL-6, TNF-a, ICAM-1, c-Jun, c-Fos, and NFkB by TF-2 as demonstrated by RT-PCR experiments. TF-2 also reduced collagen-induced swelling in mice paws as effectively as indomethacin. TF-2 decreased levels of the pro-inflammatory cytokine IL6 mRNA and protein in a proportionate manner. Analysis of clinical trial data from LPS-mediated challenge showed downregulation of COX-2, TNF-a, ICAM-1, IL-1b, IL-2, IL-6, IL-8, IL-12, and NFkB as demonstrated by real-time PCR. In summary, strong anti-inflammatory effects of TF-2 were demonstrated in cell-based assays, mouse models and clinical trials. Nutrigenomic profiling revealed suppression of multiple inflammatory pathways triggered by $\mathrm{NFkB}$ as the dominant inflammatory transcription factor.

\section{P8 \\ Screening for Glucose-6-Phosphate Dehydrogenase Deficiency in Egypt with Emphasis on Variants and Mutations Associated with Favism}

\author{
L. Hussein, A. Saleh, G. Yamama \\ Department of Nutrition, National Research Center, Giza - \\ Dokki, Egypt
}

Glucose-6-phosphate dehydrogenase [G6PD; EC 1.1.1.49] is the first enzyme in the hexose monophosphate shunt pathway, the only NADPH-generation process in mature red cells.

The enzyme is X-linked and is situated at Xq28 in the Gene map locus. In Egypt, its deficiency is the basis of favism; the hemolytic anemia following the consumption of faba beans frequently reported among the affected probands from the Mediterranean countries.

The objective of the present study was to reassess the prevalence of G-6-PD deficiency in Egypt and to characterize the common variants and mutations with emphasis on variants causing nonspherocytic hemolytic anemia. Materials and methods Nationwide screening of male children, aging few days to 18 years was carried out by recruiting healthy infants and children from 14 out of 26 administrative districts distributed all over the country.

One drop of blood was collected from the finger or heel prick for screening for G6PD deficiency by the standard filter paper spot fluorescent technique (Beutler, 1981). Detailed investigations were carried out on G-6-PD deficient probands with history of hemolytic anemia for the assay of the G-6-PD activity and characterizing its bio- chemical properties [WHO, 1967]. Genomic DNA was obtained using standard methods and the polymerase chain reaction was used to amplify portions of the coding region of the gene [Beutler; Scripps Foundation, USA].

Results: The screening of 9971 males depicted 220 cases with G-6 PD deficiency, with overall \% prevalence of $2.2 \%$ among the whole population. The G-6 PD deficiency was highest among the population of the New Valley (6.6 \% of all males); $57.4 \%$ of the G-6-PD deficient cases had at least one episode of hemolytic anemia in their life. In $83 \%$ of the cases with hemolysis, the ingestion of faba beans [favism] was the causative factor. Malaria is the underlying selective agent. for deficiency genes together with geographic association. Based on the biochemical enzyme activity and other characteristics, G6PD variants have been divided into 5 classes. The frequent forms of G6PD deficiency in Egypt are the G6PD Mediterranean (G6PD B-; (305900.0006) \& the African variant (G6PD A-; 305900.0002), which causes acute hemolysis triggered by infections; certain drugs and by fava beans. Some G6PD-deficient variants identified on the basis of their biochemical characteristics had the same mutations in the G6PD gene. The variations were attributed to posttranscriptional or posttranslational modifications of the enzyme. Hemolytic anemia was attributed to vicinity of mutation to G-6P or NADP binding site. The different hypothesis relating the episode of nonspherocytic hemolytic anemia from the near location of mutation from the glucose-6-phosphate binding site or from the putative binding site of NADP could be operative to the Egyptian G-6-PD mutations.

\section{Pg}

Prevalence and Correlates of Metabolic Syndrome in an Adult Lebanese Population

\author{
A.-M. Sibai ${ }^{1}$, O. Obeid ${ }^{2}$, M. Batal' ${ }^{2}$ N. Adra ${ }^{2}$, \\ D. El Khoury², N. Hwalla ${ }^{2}$
}

${ }^{1}$ Department of Epidemiology and Population Health, Faculty of Health Sciences, American University of Beirut, ${ }^{2}$ Department of Nutrition and Food Science, Faculty of Agricultural and Food Sciences, American University of Beirut, Lebanon

Aim: To assess the prevalence and correlates of metabolic syndrome in an adult population attending health centers in Lebanon.

Methods and Results: A sample of 499 men and women aged 18-65 years was drawn randomly from 23 health centers, selected proportionate to their distribution in the six administrative districts across Lebanon. Using standardized techniques, anthropometric measurements were taken and biochemical analyses were conducted. Based on the IDF classification criteria, the overall prevalence of the metabolic syndrome ( $>2$ factors additional to abdominal obesity) was $31.2 \%$ in the total sample and was significantly higher in men than women $(\mathrm{OR}=2.31,95 \% \mathrm{CI}=1.41-3.79)$. Abdominal obesity and low HDL-C were the factors that contributed mostly to the overall prevalence of metabolic syndrome. Lack of physical exercise associated significantly with higher odds of metabolic syndrome even after adjusting for baseline characteristics, energy consumption and fat intake $(\mathrm{OR}=2.40,95 \% \mathrm{CI}=1.02-4.51)$. 
Conclusion: While larger population-based studies are needed, the relatively high prevalence of abdominal obesity and the negative association observed between metabolic syndrome and physical activity should trigger public health policies to institute multi-component interventions promoting physical activity and weight control nationwide.

\section{P10 \\ Polyphenols and Weight Control}

D. Ivanova, Y. Kiselova, D. Dimitrov

Nutrigenomics Center Varna, Medical University, Varna, Bulgaria

Obesity is one of the major health problems worldwide, and it is a risk factor for several chronic disorders, such as cardiovascular disease, type II diabetes, or cancer, but there is no functional foods for obesity, such as there is for the metabolic disorders. However, there are evidences that control of obesity, diabetes and metabolic syndrome may be achieved by healthy diets, such as Mediterranean diet, and that it could be attributed to a great extent to the sea foods, fruits, vegetables, tea, nuts and wine bioactive substances, including polyphenols.

Human diets of plant origin contain numerous compounds, known as nutraceuticals, which beneficially affect human health. These substances include polyphenols, phytoestrogens, phytosterols, phytates and polyunsaturated fatty acids. The role of functional foods in weight control is contributed partially to polyphenols and among the healthpromoting effects of polyphenols, antioxidant, hypolipidemic and antiobesity effects in humans have become a hot issue for molecular nutrition and food research.

Tea polyphenols have been reported to inhibit fatty acid synthase, a potential therapeutic target for obesity and cancer. Polyphenol rich teas reduce dietary lipid absorption in humans, inhibiting fatty acid uptake into small intestinal brash border cells. Polyphenols reduce hepatic total cholesterol content and elevation of rat plasma triacylglycerol levels, enhance lypolysis in fat cells in mice models. Apple polyphenols improve substantially lipid status and peroxidative parameters in obese Zucker rats. Flavonoids are known to inhibit glucose uptake by adipocytes. The inhibition of digestive enzymes represents another under-reported mechanism for delivering some of the health benefits attributed to a diet rich in fruit, vegetables, teas and nuts: anthocyanins inhibit alpha-glucosidase activity and reduce blood glucose levels after starch-rich meals, a mechanism for controlling type II diabetes; a range of polyphenols (flavonoids, anthocyanidins, ellagitannins and proanthocyanidins) inhibit protease activities; proanthocyanidins inhibit gastrointestinal lipase and increase $24 \mathrm{~h}$ energy expenditure and fat oxidation in humans. The effect of wine on the improvement of cardiovascular risk factors, such as plasma lipids, haemostatic mechanisms, endothelial function and antioxidant defences is attributed to wine active principles, which besides ethanol would be also polyphenols.

Research on the effects of polyphenols provides insights into the mechanisms of prevention of diseases such as obesity, diabetes, atherosclerosis, hypertension and cancer by dietary manipulations.

\section{P11 \\ Effects of Omega-3 Fatty Acid Eicosapentaenoic Acid in the Treatment of Depression}

S. Jazayeri, S.A. Keshavarz, M. Tehranidoost, M. Jalali, M. Hosseini, A. Djazayery, H. Amini, M. Chamari, M. Peet

Department of Nutrition and Biochemistry, School of Public Health, Tehran University of Medical Sciences, Tehran, Iran

Objective: The objective of this study was to assess the therapeutic effects of omega-3 fatty acid eicosapentaenoic acid (EPA) in depression as compared to the antidepressant agent fluoxetine, the common drug for alleviation of this widespread disease.

Method: Forty outpatients (27 female and 13 male; mean \pm SD age, $34.8 \pm 8.7$ years; mean \pm SD weight, $71 \pm 15.3$ kilograms) with a diagnosis of major depressive disorder (by means of Diagnostic and Statistical Manual of Mental Disorders-IV) were randomly allocated to receive daily either $1000 \mathrm{mg}$ EPA (plusEPA ${ }^{\circledR}$, Minami Nutrition, Belgium) or $20 \mathrm{mg}$ fluoxetine, for 8 weeks. The double-dummy technique was used to double-blind the study. Patients were assessed at baseline, and weeks 2, 4, 6 and 8 after initiation of the treatment. The change in the severity of depression (assessed by means of Hamilton depression rating Scale $=$ HDRS) was the primary outcome measure.

Results: A two-way (time and treatment) repeated measures analysis of variance for HDRS was performed in 28 patients who had completed the study. There were no significant differences between the two groups in controlling depressive symptoms throughout the trial and at the end point. The response rate $(>50 \%$ decrease in baseline depression score) was higher in the EPA group (64\%), although not statistically different from that in the fluoxetine group (57\%).

Conclusion: In this 8-week trial EPA was as effective as fluoxetine in controlling depressive symptoms. As EPA is a dietary supplement it may prove more acceptable to patients than antidepressants.

\section{P12 \\ Activation of PKR in Neurons by Thiamine Deficiency}

X. Wang, Z. Fan, B. Wang, J. Luo, Z.-J. Ke

Institute for Nutritional Sciences, SIBS, Chinese Academy of Sciences, Shanghai, China

Thiamine (vitamin B1) deficiency (TD) causes mild and chronic impairment of oxidative metabolism and induces neuronal death in specific brain regions. The mechanisms underlying TD-induced cell death, however, remain unclear. The double-stranded RNA (dsRNA)activated protein kinase (PKR) has been well known for its anti-viral function. Upon activation by viral infection or dsRNA, PKR phosphorylates its substrate, the $\alpha$-subunit of eukaryotic translation factor-2 (eIF2 $\alpha$ ), leading to inhibition of translation. In response to various cellular stresses, PKR can also be stimulated by its protein activators, PACT, or its mouse homologue RAX. We demonstrated that TD in mice induced phosphorylation of PKR at Thr446 and Thr451 and phosphorylation of eIF $2 \alpha$ at Ser51 in the cerebellum and 
the thalamus. TD caused phosphorylation of PKR and eIF2 $\alpha$ as well as nuclear translocation of PKR in primary cultures of cerebellar granule neurons (CGNs). PKR phosphorylation is necessary for its nuclear translocation because TD failed to induce nuclear translocation of a T446A/T451A PKR mutant. Both PKR inhibitor and dominant-negative PKR mutant protected CGNs against TD-induced cell death. TD promoted the association between RAX and PKR. Antioxidant vitamin E dramatically decreased the RAX/PKR association and ameliorated TD-induced cell death. Our results indicate that TD-induced neuronal death is at least partially mediated by the activation of PKR.

\section{P13}

\section{Lipokines: A Link Between Aging-Related Insulin Resistance and Carcinogenesis}

\author{
D. Komninou ${ }^{1}$, J.P. Richie ${ }^{2}$, N.H.E. Mezitis ${ }^{1}$ \\ ${ }^{1}$ Mezitis Education and Research Institute, New York, NY, \\ ${ }^{2}$ Penn State College of Medicine, Hershey, PA, USA
}

Lipokines, such as leptin, TNF-alpha and adiponectin, are secreted from adipose tissue and mediate insulin-signaling pathways. Insulin resistance is a common pathology of both aging and obesity, which are strong risk factors for most forms of cancer, including colorectal cancer. We examine the link between aging and colon carcinogenesis through insulin resistance-related changes in lipokines and subsequent inflammatory processes promoting a precancerous microenvironment. This link may involve a relevant transcriptional factor, NF-kappaB, as a key inflammatory/oxidative responsive factor, which could mediate lipokine effects on colonocyte kinetics. We previously observed, using the well-validated azoxymethane (AOM)-induced colon carcinogenesis rat model, a 4-fold increase in large aberrant crypt foci (ACF) in old compared to younger animals, suggesting an aging-related increase in colon cancer susceptibility. This aging effect is apparently due to changes in post-initiation/promotion phases of carcinogenesis as no differences in AOM-induced DNA damage were observed. Dietary interventions that increase longevity, such as calorie restriction (CR) and methionine restriction (MR), inhibit colon carcinogenesis in rats. These aging-delay modalities also prevent the metabolic decline (insulin resistance) of old age by maintaining reduced levels of blood glucose, insulin, leptin and IGF-1. We found that the levels of plasma adiponectin, an important mediator of insulin sensitivity, which is reduced in obese/diabetic animals and humans, are increased in CR and MR by 2-fold and 5-fold, respectively. Interestingly, MR resulted in a 2-fold decrease in plasma leptin and a 3 -fold increase in plasma adiponectin, as early as 8 weeks on the experimental diet. Age-related upregulation of NF-kappaB with constitutive DNA binding activity is observed in colonic mucosa from old animals. These results suggest that the pathogenesis of colon cancer development involves aging-related dysregulation in lipokine production which promotes an inflammatory microenvironment and predisposes to neoplasia. Therefore, a thorough exploration of the interrelationship between the metabolic phenotype of aging and the common signaling pathways governing insulin resistance and colon carcinogenesis may allow the design of new dietary/pharmacological preventive strategies specifically targeted to the pathogenetic events in these processes.

\section{P14}

\section{Introduction of GENDI-Project: Gene-Diet Interactions in the Development of Atherosclerosis and Osteoporosis}

\author{
M. Laaksonen ${ }^{1}$, V. Mikkilä1 , L. Räsänen ${ }^{1}$, T. Lehtimäki², \\ M. Kähönen ${ }^{3}$, O.T. Raitakari4 \\ ${ }^{1}$ Division of Nutrition, University of Helsinki, ${ }^{2}$ Laboratory of \\ Atherosclerosis Genetics, University of Tampere, \\ ${ }^{3}$ Department of Clinical Physiology, Tampere University \\ Hospital, ${ }^{4}$ Centre of Applied and Preventive Cardiovascular \\ Medicine, University of Turku, Finland
}

Cardiovascular diseases and osteoporosis are both widely prevalent disorders in ageing populations, both inducing serious morbidities and death. Accumulating evidence indicate that the abnormalities in lipid metabolism, inflammation and hormonal metabolism associated with pathological changes in atherosclerosis and osteoporosis have similar characteristics. Several candidate genes have been shown to associate both with bone mass and fragility and with cardiovascular risk factors. In addition, many life-style characteristics - including physical inactivity, smoking, excessive alcohol intake and imbalanced diet - all well established risk factors for both diseases.

The main objectives of this project are to find gene-diet interactions in the development of atherosclerosis and osteoporosis and to obtain new information on the mechanisms and congruencies in the etiology of these diseases. The research expands from the Cardiovascular Risk in Young Finns Study. Young Finns is a multidisciplinary follow-up study, started in 1980 with 3,596 children and adolescents aged 3 to 18 years. The same subjects, now 30 to 45 years of age, have been followed since, and the 27 -year follow-up is being carried out in autumn 2007. The examinations have included comprehensive data collection using questionnaires, physical measurements and blood tests, including biochemical analyses on numerous risk factors and DNA testing for candidate genes. Dietary data have been collected using detailed dietary interviews and questionnaires. From 2001, the study has included ultrasound measurements of arterial function and structure. Bone density measurements have been carried out earlier in smaller subgroups and for all subjects in the latest follow-up in 2007. The longitudinal data allow us to combine genetic data with information on nutrition collected from childhood to adulthood, and relate these data to measurements of vascular structure and function and bone density performed in adulthood. The results of this research will add to the knowledge on the relationships between lifestyle and health and disease while taking into account the genetic variability. The results will provide important new data that can be utilised in planning preventive strategies against major chronic diseases. 


\section{P15}

\section{A Common Polymorphism in PPARD Gene is Associated with Type 2 Diabetes and Related Phenotypes in A Chinese Han Population}

\author{
H. $L i^{1 *}, Y . W u^{1 *}, R . \operatorname{Loos}^{2}, X \cdot \operatorname{Lin}^{1}$
}

${ }^{1}$ Institute for Nutritional Sciences, Shanghai Institutes for Biological Sciences, Chinese Academy of Sciences and Graduate School of the Chinese Academy of Sciences, Shanghai, China, ${ }^{2} \mathrm{MRC}$ Epidemiology Unit, Institute of Metabolic Science, Addenbrooke's Hospital, Cambridge, UK

Peroxisome proliferator-activated receptor (PPAR)-delta is a key regulator of fatty acid oxidation and energy metabolism. Recent studies provide evidence that PPAR-delta plays an important role in regulation of glucose metabolism and insulin sensitivity, and single nucleotide polymorphisms (rs6902123, rs2016520 and rs1053049) in PPARD gene are associated with skeletal muscle glucose uptake and increased risk of conversion from impaired glucose tolerance to type 2 diabetes. Therefore, the objective of the present study is to investigate whether these polymorphisms in the PPARD gene were associated with type 2 diabetes and its related phenotypes in Chinese population. A relatively large-scale genetic association study was conducted in a population of 3,314 unrelated Chinese Hans, including 513 individuals with type 2 diabetes, 887 individuals with impaired fasting glucose and 1914 individuals with normal fasting glucose. By comparing the individuals with type 2 diabetes and those with normal fasting glucose, we observed a strong association between rs6902123 and type 2 diabetes after adjustment for age, sex and BMI (odds ratio[OR] of TC $+\mathrm{CC}$ genotype compared with TT genotype $=1.888$, $95 \% \mathrm{CI} 1.365-2.611, \mathrm{p}=0.0001)$. Linear regression analyses revealed that $\mathrm{C}$ allele carriers $(\mathrm{TC}+\mathrm{CC}$ genotype) had significantly higher fasting glucose $(p=0.0039)$, fasting $\mathrm{HbAlc}(\mathrm{p}=0.0004)$, fasting triglycerides $(\mathrm{TG})(\mathrm{p}=0.0021)$, total cholesterol $(\mathrm{TCH})(\mathrm{p}=0.0093)$ and low-density lipoprotein $(\mathrm{LDL})(\mathrm{p}=0.0421)$ than non-carriers (TT genotypes). High-density lipoprotein (HDL) concentrations were lower in the TC $+\mathrm{CC}$ genotype carriers than in the TT genotype carriers, but the difference was not statistically significant $(\mathrm{p}=0.098)$. Neither of the other two SNPs (rs2016520 and rs1053049) was found to be associated with type 2 diabetes. In conclusion, our results suggest that PPARD is a candidate susceptibility gene for type 2 diabetes and rs6902123 polymorphism may contribute to the increased risk for type 2 diabetes and abnormality of blood glucose and lipid profile in the Chinese population.

\section{P16}

\section{Genetic Variation of 17 Single Nucleotide Polymorphisms in the Greek Population}

\author{
E. Louizou ${ }^{1,2}$, P. Carro//2, M. Samiotakis ${ }^{2}$, \\ M. Kambouris ${ }^{2,3}$
}

${ }^{1}$ Harokopio University, Athens, ${ }^{2}$ Geno-Type Biotechnology, Athens, Greece, ${ }^{3}$ Yale University School of Medicine, CT, USA

Objective: To determine the allele frequencies of 17 single nucleotide polymorphisms (SNP) in unrelated subjects in the Greek population. The genes and respective functional SNPs analyzed were: MTHFR (C677T, A1298C), MTRR (A66G), MTR (A2756G), CBS(C699T), MnSOD (C-28T, T175C), IL6 (G-174C), TNFa (G-308A), APOC3(C3175G), CETP (G279A), LPL (C1595G), ACE (Ins/Del), VDR (Taq1, Bsm1, Fok1), PPAR- $\gamma$ (Pro12Ala).

Methods: DNA samples from six hundred and fifty individuals were utilized. Genotypes were determined by the Luminex DNAxMAP [Multiple Analyte Processing] system which is a multiplex microsphere-based platform capable of analyzing and reporting multiple SNPs simultaneously. Each SNP is targeted by a direct probecoupled microsphere.

Results: The genotype frequencies of 14 polymorphic loci are similar to those reported for several other Caucasian populations. However a significant difference in allelic frequency was found for three SNPs: IL6 (G-174C), MTHFR (C677T) and PPAR- $\gamma$ (Pro12Ala). The allelic frequencies of the less common allele were $37.59 \%$, $41.67 \%$ and $20.88 \%$ respectively whereas the reported frequencies for Caucasians were $53.3 \%, 24.6 \%$ and $7.5 \%$.

Conclusion: Predictive Genomics utilizing disease associated SNP profiling can indicate increased risk due to genetic predisposition to common multifactorial-polygenic diseases such as Cardiovascular disorders, Osteoporosis, Insulin Resistance, Inflammatory diseases etc. Individuals at increased risk can target presymptomatic management and therapeutic modalities towards the biochemical pathways that are affected by the predisposing SNPs. Establishing population frequencies for disease associated SNPs is of utmost importance for proper evaluation of SNP profiling and risk assignment. Statistically significant differences for disease associated SNPs are generally not expected amongst various ethnic populations and are surprising when found. Sample numbers, diagnostic methodologies and population peculiarities should be taken into account when determining whether statistically significant differences in SNP frequencies exist.

\footnotetext{
*These authors contributed equally to this work.
} 
P17

\section{Effect of Zinc, Selenium and Copper on Telomerase Gene Expression in Breast Cancer Cell Line}

\section{S.A. Mahboob, N. Zarghami, J. Asadi \\ Nutritional Reaserch Center, faculty of Health and Nutrition, Tabriz University of Medical Sciences, Tabriz, Iran; Department of Clinical Biochemistry and RIA, Drug Applied Research Center, Tabriz University of Medical \\ Sciences, Tabriz, Iran}

Background and Objectives: Breast cancer is the most common cancer in women. The aim of this study was to evaluate the effect of Zinc, Selenium and Copper on telomerase gene expression in breast cancer cell line.

Material and Methods: T47D breast cancer cell line was cultured and treated with different concentrations of trace elements ( $\mathrm{Zn}$, $\mathrm{Cu}, \mathrm{Se}$ ). The kinetic study was carried out on telomerase gene expression. Relative telomerase activity (RTA) of cell line (T47D) was measured by TRAP assay method.

Results: After being treated with $100 \mu \mathrm{M} / \mathrm{L}$ Zn So4, telomerase activity of T47D cells for 6 hours was markedly increased (5.2 fold). After being treated with $100 \mu \mathrm{M} / \mathrm{L}$ Zn So4 for 24 hours and $500 \mu \mathrm{M}$ /L Zn So4 for 6, 24 hours, telomerase activity was $0.76,0.39$ and 0.12 respectively (control 49.2). After being treated with $10 \mu \mathrm{M} / \mathrm{L} \mathrm{Cu}$ So4, telomerase activity of T47D cells for 6 hours was markedly increased (3.67 fold). However, there was no significant effect at concentration of $3 \mu \mathrm{M} / \mathrm{L}$ of $\mathrm{Cu}$ So 4 at time kinetic of $6 \mathrm{hr}$. The concentrations of 3 and $10 \mu \mathrm{M} / \mathrm{L}$ had no effect at time $24 \mathrm{hr}$. After being treated with 10, 30 micromole/L selenium-1- methuonin, telomerase activity of T47D cells were markedly inhibited. Telomerase activity of T47D cells for 24 hours were $0.93,0.60$; for 48 hours were $0.76,0.12$ respectively (control 49.2).

Conclusion: It is speculated that $\mathrm{Se}, \mathrm{Zn}$ and $\mathrm{Cu}$ may have inhibitory effect on telomerase gene expression in invtro model of breast cancer and could be a target for therapeutic purpose.

\section{P18}

DNA-Customized Genotrim [Neuronal Dopamine Release Activator] Results in Significant Reductions in Weight, Appetite, Sugar Cravings in an Obese Population in the Dietary Investigation to Evaluate Treatments (D.I.E.T.) Pilot Study. Nutrigenomic Correlates of Reward Deficiency Syndrome (RDS)

\author{
K. Blum 1,2,5, B. Meshkin'2, T.J. Prihoda ${ }^{3}$, B.W. Downs, \\ R.L. Waite ${ }^{5}$, E.R. Braverman 6 , L. White 7,8 \\ ${ }^{1}$ Department of Physiology \& Pharmacology, Wake Forest \\ University School Of Medicine, Winston -Salem, NC, \\ ${ }^{2}$ Salugen, Inc. San Diego, CA, ${ }^{3}$ Department of Pathology, \\ University Of Texas Health Science Center, San Antonio, \\ TX, ${ }^{4}$ Allied Nutraceutical Research, Lederach, PA, \\ ${ }^{5}$ Genwellness, Inc San Diego, CA, ${ }^{6}$ Path Research \\ Foundation, New York, New York, ${ }^{7}$ Baylor College of \\ Medicine. Houston TX, ${ }^{8}$ DNA Services of America, \\ Lafayette, LA, USA
}

Background: Obesity is a biogenetic condition involving both environmental and genetic antecedents. Like certain health conditions that were once classified as purely behavioral abnormalities, obesity is now accurately characterized as a disease with biological and genetic factors. It has been reported that in both Caucasian women and men, heritability for BMI was 0.58 and 0.63 , for body fat $\%, 0.59$, and 0.63 , and for lean body mass 0.61 and 0.56 , respectively. Because of the complexity of obesity and related conditions involving reward deficiencies, it is likely that more than one defective gene is involved. However, work from Volkow's lab showed a dopamine D2 receptor paucity in subjects with Reward Deficiency Syndrome (RDS) vs. non-RDS subjects by PET scan. The FDA has recently rejected rimbanant, a CB1 antagonist and an inverse agonist causing dopamine release blockade at the mesolimbic nucleus accumbens (NAc) (a potential new anti-obesity drug) because of potential adverse effects including depression and suicidal ideation. Objective: Searching for a better anti-obesity agent, we systematically evaluated the affects of a novel DNA customized nutraceutical (Genotrim ${ }^{\circledR}$ possessing dopaminergic release activation properties), on weight management outcomes and attempted to correlate at least five candidate genes with these multiple outcomes. Methods: A total of 1,058 self-identified obese subjects of Dutch-decent were genotyped for this study. These individuals were administered a customized nutraceutical, GenoTrim, depending on their DNA profiles. Out of these subjects, we identified 27 subjects who responded to the survey about their experience (a typical 3\% marketing response rate). Responses derived from a modified standardized questionnaire and a Likert scale designed to obtain information were entered into a computer database and analyzed for significance.

Results: Simple t-tests comparing a number of parameters before and 80 days on Genotrim ${ }^{\circledR}$ were performed. The significant results are as follows: weight loss $(\mathrm{p}<0.008)$; sugar craving reduction $(\mathrm{p}<0.008)$; appetite suppression $(\mathrm{p}<0.004)$; snack reduction $(p<0.005)$; reduction of late night binging $(p<0.007)$; increased perception of over-eating $(p<0.02)]$; increased energy $(p<0.004)$; enhanced quality of sleep $(p<0.02)$ and increased happiness $(p<0.02)$. In this study, polymorphic negative correlates for the can- 
didate genes were obtained for the PPAR gamma 2 (Fat Regulator gene), MTHFR (Cell Repair Gene), 5-HT2a (Nervous Eating Gene), and DRD2 (Sweet Tooth Gene) and the Leptin OB (Obesity Risk Gene) genes with positive clinical parameters tested. The multiple regressions identified several outcomes that could be jointly predicted by multiple variables significantly. Both, days on treatment and compliance with instructions jointly predicted exercise change $(\mathrm{r}$-squared $=$ $0.58, \mathrm{p}=0.0004)$. Both the fat regulator gene polymorphism and compliance with instructions jointly predicted change in getting along ( $\mathrm{r}$-squared $=0.42, \mathrm{p}=0.007$ ). Both the nervous eating gene and $\mathrm{OB}$ risk gene jointly predicted waist size change $(\mathrm{r}$-squared $=0.56, \mathrm{p}=$ $0.024)$. The sweet tooth gene (DRD2) polymorphism (A1 allele) significantly predicted the number of days on treatment (r-squared 0.42 , $p=045$ ). All other outcomes evaluated, were only significant for the univariate results given above.

Conclusion: We are proposing herein, that short term RDS therapy (6-12 months) [whereby the individual is still using addictive substances and are dependent on these substances], utilize a cannabinoid type 1(CB1) receptor antagonist such as rimonabant (SR141716A) to block the neuronal release of dopamine (DA) in the nucleus accumbens (NAc). By blocking neuronal DA release one would expect that an individual's reinforcing effects derived from any unnatural reward (i.e. sugar, nicotine, alcohol etc) will be dampened or even eliminated. This should result in a reduction of substance seeking behavior. Additionally we are also proposing, long term RDS therapy (whereby an individual may possess candidate reward gene polymorphisms [i.e. serotonergic,endorphinergic, gabaergic, dopaminergic etc] ultimately resulting in physiological brain derived reward deficits predisposing individuals to RDS behaviors (substance seeking), utilize a dopaminergic type D2 receptor agonist such as Genotrim ${ }^{\circledR}$ to activate the neuronal release of dopamine (DA) in the nucleus accumbens (NAc). By activating neuronal DA release one would expect that an individual's reinforcing effects derived from any natural reward (i.e. daily experiences, food, sex, love, etc.) will be enhanced. This should also result in a reduction of substance seeking behavior. We cautiously suggest that DNA directed targeting of certain regulator genes along with customized nutraceutical intervention provides a unique framework and strategic modality to combat obesity using nutrigenomic principles.

\section{P19 \\ Effect of Green Tea Extract on Colon Inflammation and Gene Expression in mdr1a-/- Mice* \\ K. Nones ${ }^{1}$, Y.E.M. Dommels',2, S. Marte//1, C. Butts ${ }^{1}$, W.C. McNabb ${ }^{3}$, Z. Park-Ng ${ }^{3}$, M.P.G. Barnett ${ }^{3}$, S. Zhu ${ }^{4}$, D. Hedderley', N.C. Roy ${ }^{3}$ \\ ${ }^{1}$ Crop \& Food Research, New Zealand, ${ }^{2}$ Unilever Food \& Health Research Institute, The Netherlands, ${ }^{3}$ Food, Metabolism \& Microbiology, AgResearch Limited, New Zealand, ${ }^{4}$ Faculty of Medical and Health Sciences, The University of Auckland, New Zealand}

Inflammatory bowel disease (IBD) is thought to result from the dysregulation of a combination of functional pathways; immunoregulation, maintenance of mucosal barrier integrity, microbial recognition and clearance, and/or homeostasis. Green tea extracts are non-nutritive polyphenolic-flavonoid compounds known to have anti-inflammatory activity, but the mechanism(s) of this are not fully understood. Mdr1a-/mice spontaneously develop intestinal inflammation predominantly in the colon and therefore are a relevant model for IBD. This study tested whether addition of green tea polyphenols to the food of mdr1a-/- mice would alleviate colonic inflammation, allowing us to investigate the effect of dietary green tea polyphenols on relevant gene expression in colon tissue. This approach was designed to give insight into how this dietary compound might influence the metabolic pathways involved in the inflammatory response in mdrla-/- mice. Twelve mdr1a-/- mice were randomly assigned to each of two experimental diets: control (AIN-76A), or control (AIN-76A) with $0.6 \%$ green tea extract (a polyphenol extract containing $35 \%$ epigallocatechin gallate). Mice were monitored from the age of 7 to 24 weeks, at which time colon tissues and blood were collected for histological and gene expression evaluation. Green tea extract significantly reduced the histological signs of colon inflammation and serum amyloid A concentration in the plasma of mdrla-/- mice $(\mathrm{P}<0.05)$. These results confirm the antiinflammatory effect of dietary green tea extract. Using the Ingenuity Pathways Analysis program, microarray data showed a total of 712 genes differentially expressed in the colon of mdr1a-/- mice as a result of dietary green tea extract that met the criteria for pathway analysis. Pathways involved in xenobiotic metabolism (five pathways) and immune and inflammatory response (eight pathways) were affected by green tea extract. Further research on the significance of these pathways is warranted; but these results have implications in terms of potential dietary supplements for people with IBD and demonstrate the importance and potential of nutrigenomic studies in understanding nutrient/gene interactions.

*Nutrigenomics New Zealand.

\section{P20}

\section{Weight Loss and Telomere Length}

\author{
N. O'Callaghan, B. Benassi, P. Clifton, M. Noakes, \\ M. Fenech \\ CSIRO Human Nutrition \& FSA, Adelaide, Australia
}

Background: Telomeres are composed of long hexamer (TTAGGG) repeats that protect against spontaneous DNA damage such as telomere end-fusions which lead to chromosomal instability and increase the risk for cancer. During each cell division 50-250bp of the telomere 'chromosome cap' is lost. When telomeres become too short the cell senesces and programmed cell death occurs. Shortened telomeres also cause genome instability and are observed in many carcinomas such as those of the colorectum, pancreas, bone, lung, bladder and kidney. The purpose of this study was to investigate the telomere length of mid-rectal biopsy samples and to determine if weight loss influences telomere length.

Methods: Mid-rectal biopsies were collected by sigmoidoscopy forceps. Appropriate consent was obtained from volunteers. Telomere length was measured by determining the number of TTAGGG hexamer repeats using quantitative real-time PCR. We modified the Cawthon assay to obtain an absolute measurement of telomeric repeats. Mid-rectal biopsies were taken at three time points through- 
out the study; week 0 , week 12 and week 52 during programmed weight loss.

Results: Telomere length was correlated with BMI $(r=-0.13$, $\mathrm{p}<0.05)$. Weight loss occurred on either a high protein high red meat diet or a high carbohydrate diet. The results indicate that telomere length is increased after 12 weeks and 52 weeks on the weight loss diets $(\mathrm{P}<0.0001)$. Furthermore, weight loss was correlated with change in telomere length $(\mathrm{r}=0.7, \mathrm{p}<0.01)$.

Conclusion: Weight loss diets appear to increase telomere length in mid-rectal biopsies. These preliminary data suggest that weight loss may contribute to the prevention of telomere shortening which is an important event in carcinogenesis. The significance of these results may become clearer once the mechanism for the observed telomere length increase is elucidated. Possible mechanisms include reduced cell division and oxidative stress.

\section{P21 \\ ACACB and MLYCD Gene SNPs are Associated with Body Weight in Normal Females \\ A.K. Lee1, T. Kyriakou' ${ }^{1}$ D. Ge ${ }^{2}$, G. Liü ${ }^{3}$, H. Snieder ${ }^{3}$, T.D. Spector ${ }^{4}$, S.D. O'De// ${ }^{1}$ \\ ${ }^{1}$ Nutritional Science Division, King's College London, UK, ${ }^{2}$ Center for Population Genomics \& Pharmacogenetics, Duke University, Durham, NC, USA, ${ }^{3}$ Dept. Epidemiology, University Medical Center Groningen, The Netherlands, ${ }^{4}$ Twin Research \& Genetic Epidemiology Unit, King's College London, UK}

Accumulation of long-chain fatty acyl CoA (LC-CoA) in the hypothalamus signals energy surfeit and leads to inhibition of feeding. We proposed that the level of expression of enzymes which respectively synthesise and degrade malonyl CoA, a potent inhibitor of fatty acid transport into the mitochondria by carnitine palmitoyltransferase (CPT1), could modulate the accumulation of esterified fatty acids and thereby influence feeding behaviour and body weight. The formation of malonyl CoA is catalysed by acetyl-CoA carboxylase (ACC) and its degradation by malonyl CoA decarboxylase (MCD). We investigated whether potential functional SNPs in the promoters of ACACB and MLYCD genes were associated with anthropometry, body fat and serum leptin in 2614 healthy Caucasian females from the Twins UK cohort (mean age 47.3 \pm 12.6 years). For ACACB rs16939972, we found significant associations with weight, total body fat, fasting glucose and HOMA (Ps $=0.002-0.021)$. For MLYCD rs 880088 we found significant associations with leptin, BMI, weight, waist circumference, total and central body fat, fasting insulin and HOMA (Ps $=0.005-0.03)$. We then tested the effect of both SNPs on activity of a luciferase reporter gene in transiently transfected HepG2 cells. The constructs contained approx. $1 \mathrm{~kb}$ regions upstream of the transcriptional start site, carrying either allele. There was no significant difference in luciferase reporter gene activity with respect to the ACACB rs16939972 allele. Preliminary results suggest the MLYCD rs880088 C-allele has higher activity than the G-allele, which is in line with the results of the association study. In conclusion, both ACACB and MLYCD promoter SNPs are associated with anthropometry, body fat and insulin sensitivity. A SNP in the
MLYCD promoter may influence gene expression and contribute to variation in body weight.

\section{P22}

The Effect of Vitamin D Supplementation on Serum 25- Hydroxy Vitamin D and Parathyroid Hormone Levels in Obese and non Obese Reproductive Age Women

\author{
A. Ostad Rahimi ${ }^{1}$, S.A. Mahboob², \\ M. Abbasalizad Farhanghi ${ }^{3}$ \\ ${ }^{1}$ Nutritional Reaserch Center, Tabriz university of Medical \\ Sciences, Faculty of Health \& Nutrition, ${ }^{2}$ Nutritional \\ Research Center, Tabriz University of Medical Sciences, \\ Tabriz, Iran, ${ }^{3}$ Department of Biochemistry and clinical \\ nutrition, Faculty of Health \& Nutrition, University of Tabriz \\ Medical Sciences, Nutritional Research Center, Tabriz, Iran
}

Background: Although obesity has been suggested to alter vitamin D endocrine system, The effect of vitamin D injection on Serum 25- Hydroxy Vitamin D And Parathyroid Hormone levels In obese and non obese Reproductive Age Women has not been clarified.

Objective: The objective was to study the effect of vitamin D injection on Serum 25- Hydroxy Vitamin D And Parathyroid Hormone Levels In obese and non obese Reproductive Age Women in order to asses whether there is a need to adjusting the doses of vitamin D administered to this group according to their BMI.

Design: This Interventional study was performed on 86 reproductive age women (17-50 years) which were randomly selected from general population of Tabriz city. They were assigned into two experimental groups. Obese group with stage 1 and 2 obesity (BMI: 30-34.9 and $35-39.9 \mathrm{~kg} / \mathrm{m} 2$ respectively) and non obese group with normal weight (BMI: $18.5-24.9 \mathrm{~kg} / \mathrm{m} 2$ ). Weight was measured to the nearest $0.1 \mathrm{~kg}$ using a calibrated Seca scale while subjects had light clothes and no shoes. Height was measured using a cotton ruler which was stick to wall. Body mass index was calculated based on weight and height results .Biochemical parameters were measured before and after injection of 600000 units of vitamin D. Serum 25 hydroxy vitamin D was measured by Chemiluminescence Immuno Assay method (CLIA), serum PTH by Enzyme linked immunoassay technique (ELISA), alkaline phosphatase by Enzymatic method and serum Calcium and Phosphorous by colorimetric method.

Results: Thirty one women (36\%) had severe and moderate vitamin D deficiency, thirty one (36\%) mild vitamin D deficiency and twenty four (28\%) vitamin D adequacy prior to vitamin D injection. At the end of the study 6 women (7\%) still had sever and moderate vitamin D deficiency and 16 women $(19 \%)$ had mild vitamin D deficiency. Baseline level of serum 25 hydroxy vitamin D in obese subjects was lower than non obese subjects, But this wasn't statistically significant. Baseline concentration of serum PTH in obese subjects was significantly lower than non obese subjects $(\mathrm{P}<0.05)$. Vitamin $\mathrm{D}$ injection caused a strong modification in vitamin $\mathrm{D}$ endocrine system. After vitamin D injection there was a significant increase of serum 25 hydroxy vitamin D and calcium and phosphorous levels and significant decrease in serum PTH and alkaline phosphatase levels. The Response of serum 25 hydroxy vitamin $\mathrm{D}$ to vitamin $\mathrm{D}$ injection in obese subjects was weaker than non obese subjects, However this 
difference wasn't statistically significant. Mean elevation in serum 25 hydroxy vitamin D level among women who had severe and moderate vitamin D deficiency was $12.22 \mathrm{ng} / \mathrm{ml}$ whereas women with mild vitamin D deficiency and vitamin D adequacy showed 10.98 and 1.6 $\mathrm{ng} / \mathrm{ml}$ elevation in serum 25 hydroxy vitamin D level respectively ( $\mathrm{P}<0.05$ for difference between groups).

Conclusion: Low serum vitamin D and high parathyroid hormone levels can be modified by vitamin $\mathrm{D}$ injection in both obese and none obese women but obese women need more vitamin D due to more adiposity.

\section{P23}

\section{The Presence of Genetic Variation at the Perilipin Locus Modulates Postprandial Triglyceride Metabolism in Two Caucasian Populations}

\author{
P. Perez-Martinez ${ }^{1,2}$, N. Yiannakouris ${ }^{1,3}$, \\ J. Lopez-Miranda', D. Arnett', J. Delgado-Lista ${ }^{2}$, M. Tsai ${ }^{5}$, \\ F. Lopez-Segura², R. Straka', J. Delgado-Lista², \\ B. Garcia-Bailo', F. Perez-Jimenez ${ }^{2}$, J.M. Ordovas ${ }^{1}$
}

${ }^{1}$ Nutrition and Genomics Laboratory, JM-USDA Human Nutrition Research Center on Aging at Tufts University, Boston, MA, ${ }^{2}$ Reina Sofia University Hospital, Lipids and Atherosclerosis Research Unit. University of Cordoba. Ciber Fisiopatologia Obesidad y Nutricion (CB06/03) Instituto Salud Carlos III. Spain, ${ }^{3}$ Department of Nutrition and Dietetics, Harokopio University of Athens, Greece, ${ }^{4}$ Department of Epidemiology, University of Alabama, Birmingham, AL, ${ }^{5}$ Department of Laboratory Medicine and Pathology, University of Minnesota, Minneapolis, MN, ${ }^{6}$ Department of Experimental and Clinical Pharmacology, University of Minnesota, USA

Perilipins are proteins localized at the surface of the lipid droplet in adipocytes, playing a role in the regulation of triglyceride deposition and mobilization. Several perilipin (PLIN) polymorphic sites have been studied for their potential use as markers for obesity and metabolic syndrome. Our aim was to examine whether the presence of several polymorphisms at the perilipin (PLIN) locus (PLIN1: 6209T $>$ C, PLIN4: 11482G $>$ A, PLIN5: 13041A $>$ G, and PLIN6: $14995 \mathrm{~A}>\mathrm{T}$ ) could influence postprandial lipoprotein metabolism in two different Caucasian populations.

Subjects and Methods: 88 healthy Spanish subjects and 271 US subjects from the general population underwent an oral fat-load test in two independent studies. Blood samples were taken every $1 \mathrm{hr}$ until $6 \mathrm{hr}$, and every $2.5 \mathrm{hr}$ until $11 \mathrm{hr}$ in the Spanish population and at time $0,3.5$ and $6 \mathrm{hr}$ in the US subjects. Total cholesterol and triacylglycerols (TAGs), and TAGs in triacylglycerol-rich lipoproteins (TRL) (large and small triacylglycerol-rich lipoproteins) were determined.

Results: Subjects carrying the T/T genotype at the PLIN 1 displayed greater postprandial concentrations of large-TRL TAGs (Spanish subjects: $p=0.024$ and US subjects: $p=0.005$ ) than did carriers of the minor allele $\mathrm{C}(\mathrm{T} / \mathrm{C}$ and $\mathrm{C} / \mathrm{C})$. The same behavior was observed in the Spanish population at the PLIN 4 variant $(p=0.015)$. In both groups, individuals carrying the $\mathrm{T} / \mathrm{T}$ and $\mathrm{G} / \mathrm{G}$ genotypes at the PLIN1 and PLIN4 respectively had significantly higher postprandial concentrations of plasma TAGs $(\mathrm{p}<0.05)$ and also displayed greater concentrations of small-TRL TAGs than did carriers of the minor alleles $\mathrm{C}$ and $\mathrm{A}$ (Spanish: $\mathrm{p}=0.020$ and $\mathrm{p}=0.008$, respectively; US: $p=0.021$ and $p=0.035$, respectively). There was no statistically significant association between any of the variables examined at PLIN5 and PLIN6 polymorphisms.

Conclusion: These two studies suggest that the presence of the genotypes $\mathrm{T} / \mathrm{T}$ and $\mathrm{G} / \mathrm{G}$ at the PLIN1 and PLIN4 respectively are associated with a higher postprandial response. Thus, the allele variability in the PLIN1 6209T $>$ C and PLIN4 11482G $>$ A polymorphisms in the perilipin gene may partly explain the interindividual differences in postprandial lipemic response in two different Caucasian populations.

\section{P24 \\ Sesame Oil Lignans: Effects of Gene Expression and Lipid Metabolism in Fish}

S. Trattner ${ }^{1}$, A. Kamal-Eldin'1 , A. Moazzami ${ }^{1}$, E. Brännäs ${ }^{2}$, B. Ruyter ${ }^{3}$, T. Gjøen ${ }^{4}$, J. Pickova ${ }^{1}$

${ }^{1}$ Department of Food Science and ${ }^{2}$ Dept of Wildlife, Fish and Environment, Swedish University of Agricultural Sciences, Uppsala, ${ }^{3}$ AKVAFORSK, Inst. of Aquaculture Research, Ås, ${ }^{4}$ Department of Pharmaceutical Bioscience, University of Oslo, Oslo, Norway

Sesame oil is rich in lignans, a major one being sesamin. These are metabolically active compounds. The level of sesamin in sesame oil is $0.2-0.7 \%$. The effects of inclusion of a mixture of sesamin and episesamin on gene expression and lipid metabolism in fish fed diets based on vegetable oils of different fatty acid composition were examined. Sesamin/episesamin was included at $2 \%$ level of fat content in the diet. The oils used in the feed were $100 \%$ linseed oil or a mixture of linseed and sunflower oils (60:40, w/w). Addition of sesamin/episesamin increased eicosapentaenoic acid and docosahexaenoic acid (EPA and DHA) percentages in white muscle phospholipid and triacylglycerol by $20-30 \%$. The concentrations of tocopherols in different tissues were slightly affected by the inclusion in the diets. Sesamin and episesamin were detected in muscle and liver tissues of the experimental fish.The expression of PPAR $\alpha$ was significantly down regulated in liver of fish fed mixed plant oil with sesamin. Expression of PPAR $\beta$ and PPAR $\gamma$ was not affected by the inclusion of sesamin in any tissues. The regulation of PPAR $\alpha$ in liver is opposite to that observed in rats. Expression of PPAR $\alpha$ has also been reported to be down regulated in salmon fed 3-thia fatty acids compounds that has been associated with up regulation of PPARs in mammals. The differences in the metabolism and bioactivirty of xenobiotic compounds between fish and mammals are obvious and not fully clarified. 


\section{P25}

\section{Dietary Shift and Obesity. Is there a Role for Genetics?}

\author{
A. Rodríguez-Ojea, S. Jimenez, M.E. Díaz \\ Institute of Nutrition and Food Hygiene, Havana, Cuba
}

A National Survey in 1995 was developed to find out the prevalence of overweight and obesity in adults 20 to $65 \mathrm{y}$ in a representative sample of the Cuban adult population.

Prevalence of obesity (BMI $>30)$ was $11,1 \%(9,9-12.5)$ in females and $6,0 \%(5,2-6.8)$ in males. Food apparent consumption averaged less than $2000 \mathrm{kcal} / \mathrm{d}$, while carbohydrates supplied nearly $76 \%$ of total energy.

In 2001, data from the Second National Survey showed an increasing prevalence of obesity in females $(15,4 \%)$ and in males $(7,95 \%)$. Data on the average of apparent food consumption (2595 kcal/d) a figure $30 \%$ higher and carbohydrates supplied $78 \%$ with a large contribution of sugar as well. Therefore, overweight and obesity is now considered as a health problem in Cuba.

The "rebound effect" after the end of the economic crisis on the nineties, may have triggered genetic mechanism promoting the increasing body weight (42,5\% overweight/obese), and probably also the growing prevalence of the waist to hip ratio syndrome, particularly in the group of 60 years and beyond and in the group with the lower educational level.

Growing availability of foods and energy is the major risk factor associated. In 2004, data from apparent food consumption averaged $3226 \mathrm{kcal} / \mathrm{d}$. However, energy from fat kept low, ranging from 11,4 to $14,4 \%$ of the total amount of energy, while carbohydrates kept high, supplying $77 \%$. It is presumably that the apparent consumption observed shift on energy from carbohydrates, played a relevant role on the genetic expression of the obese-prone population in Cuba.

\section{P26 \\ 'Israeli Gender Paradox' - Much Higher Women's Risk with the Same Diet, Especially for Cancer}

\section{N. Shapira}

Tel Aviv University, Ramat Aviv, Israel

Background: Low health status despite 'good' diet - formerly called the 'Israeli Paradox,' attributed to high n-6 polyunsaturated fatty acid (PUFA) intake (12 kcal\%) - is now shown to be lead by women, especially with cancer.

Objective: To evaluate relative mortality risks of subpopulations (sex and ethnic) for disease (cancer, ischemic heart [IHD], cardiovascular $[\mathrm{CVD}]$ ) and relationship to increasing dietary n-6 PUFA vs. traditional Mediterranean diet.

Methods: Comparison of mortality data from the World Health Organization (European Average [Eur-A] and international) and Israel Cancer Registry, and of Israeli nutritional data from a recent national survey (MABAT).

Results: Women rank worse, for life expectancy than Eur-A (81.8 vs. $82.0 y)$ - while Israeli men rank better ( 77.6 vs. $75.9 y)$ - and for all-cancer mortality ( 15 th vs. $37^{\text {th }} / 44$ countries), compared to IHD and CVD with lower rates and ranks and smaller gender gaps (34th vs. 38 th, 42 th vs. 44 th, respectively). Breast cancer mortality in Israeli women is $19 \%$ higher than Eur-A, prostate cancer mortality in Israeli men 25\% lower. Israeli-Jewish women have had much higher cancer prevalence (1:3) than Israeli-Arab women (1:6), despite similar dietary composition, save for higher n-6 PUFA and lower monounsaturated fatty acid (MUFA)-to-PUFA ratio (1.2 vs. 1.7:1). Israeli-Arab women, still consuming more n-9 MUFA-rich olive oil - found to be cancer-preventive - have had 1.7 times lower cancer mortality than Israeli-Jewish women, but a faster-growing rate (increasing 5.3 vs. decreasing 3.3\%, 1980-2000) concurrent with increasing intake of high-n-6 PUFA oils substituting for olive oil. Inadequate protective n-3 PUFA could represent another nutritional risk factor: while reported intake among Israeli-Jewish women $(1.6 \mathrm{~g} / \mathrm{d})$ is within the recommended range, the $n-6: n-3$ PUFA ratio $(8.3: 1)$ is much higher than suggested for cancer prevention.

Discussion: The findings may indicate a 'gender paradox' of sex-related differential risk with increasing dietary n-6 PUFA which, when unopposed by n-3 PUFA or n-9 MUFA, affects women's health more than men's, especially vis-à-vis cancer mortality. Research has demonstrated hormonal and sexual dimorphism in lipid and n-6 PUFA metabolism and carcinogenicity, suggesting sex and/or genetic predisposition (presumably high BRCA mutations in Ashkenazi Jews) does not preclude the role of nutrition-based prevention, and may in fact increase its importance.

Conclusions: This is the first time sexual dimorphism has been suggested as a modulating factor of dietary effects on public health. In view of the global increase in n-6 PUFA consumption, Israeli women may represent a case study for research into gender-based nutritional intervention, especially as related to cancer epidemiology.

\section{P27 \\ ANGPTL4 Variants are Associated with Lower Plasma Triglyceride Levels and Improved Postprandial Responses, but Increased CHD Risk, Independent of Triglycerides}

\author{
M. Smart, E. Presswood, J.A. Cooper, F. Drenos, \\ J. Palmen, S.E. Humphries, P.J Talmud \\ University College London, London, UK
}

Background: The adipokine angiopoietin-like 4 (Angptl4), is a fasting-induced inhibitor of lipoprotein lipase, influencing plasma triglyceride (TG) levels.

Methods and Results: The association of 6 tSNPs rs4076317, rs7255436, rs1044250, rs11672433, rs7252574, rs1808536 (r2 = 92 $\%$ ) and the recently identified E40K with plasma lipids and CHD risk was analysed in prospective analysis of 2725 middle aged men. Only rs 1044250,T266M $\quad(\mathrm{MAF}=0.30 \quad(95 \% \mathrm{CI} \quad 0.29-0.31)$ and $\mathrm{E} 40 \mathrm{~K}$ $(\mathrm{MAF}=0.02(95 \% \mathrm{CI} 0.02-0.02)$ showed significant TG-lowering $(-11.54 \% \mathrm{p}<0.004$ and $-20.4 \%$ in $(\mathrm{p}<0.0001)$, respectively. Haplotype analysis revealed no additional TG-lowering effects, but compared to EE/TT men those with genotype EK/TM or EK/MM had $19.6 \%(\mathrm{p}>0.0001)$ and $25 \%(\mathrm{p}<0.0001)$ lower TG levels, respectively. Compared to T266 homozygotes and after adjustment for TG 
levels, M266 carriers showed higher CHD risk $(\mathrm{HR}=1.36(1.06-1.73$; $\mathrm{p}=0.02)$. In two European studies there was a rare allele frequency gradient from North to South. In the HIFMECH case: control study $(\mathrm{N}=518 \& 561)$ the association of M266 with risk was confined to the Northern centres $[\mathrm{HR}=1.59(1.04-2.42)]$. In the EARSII offspring case: control study $(\mathrm{N}=332 \& 370)$ E40K showed significant association with fasting HDL levels $(\mathrm{p}=0.01)$. M266 homozygotes, compared to TT and MT men, showed significantly lower AUC TG and glucose after ( $p=0.009$ and $p=0.017$, respectively), but only in the healthy young 'cases' (defined on the basis of their fathers early MI).

Conclusion: Angpt14 K40 and M266 behave as loss-of-function variants which protect against traits of the metabolic syndrome. While E40 is in the coil-coil domain, a region implicated in LPL inhibition, T266 lies in the fibrinogen domain which in angiopoietins is thought to be involved in angiogenesis and the association of T266M with higher risk suggests that Angptl4 may have angiogenic effects..

\section{P28 \\ Perinatal Essential Fatty Acid Deficiency in Mice Depresses Hepatic mRNA Expression of Several Fatty Acid Regulating Genes}

\section{B. Strandvik1, V. Palsdottir ${ }^{1}$, A. Wickman², B. Gabrielsson ${ }^{2}$}

${ }^{1}$ Department of Pediatrics and ${ }^{2}$ Division of Metabolism and Endocrinology, Sahlgrenska Academy, Göteborg

University, Göteborg, Sweden

Background: The global epidemics of obesity have been proposed to be associated with the increase of n-6 fatty acids in Western diet. Fatty acids regulate gene expression and during pregnancy and early life changes in gene expression might be permanent, i.e. cause programming of diseases in adults. By giving a diet rich in saturated fat and deficient in essential fatty acids (EFA), we reflect the more old fashioned diet in Europe. We have previously reported that EFA deficiency in the perinatal period influenced hepatic mRNA expression of peroxisome proliferator-activated receptors (PPARs) and a co-activator $(\mathrm{PGC} 1-\alpha)$ at 3 weeks of age. These mice were also resistant to diet-induced obesity as adults. Aim: To further explore the influence on hepatic mRNA expression of other nuclear receptors and genes involved in fatty acid synthesis and metabolism. Methods: Mice of C57BL/6 strain were given EFA deficient (EFAD) or control diet from day 15 of pregnancy through lactation. The pups were killed at 3 weeks of age and liver was frozen in $-70^{\circ} \mathrm{C}$ until analysis. Total mRNA from liver was isolated and mRNA levels of genes involved in fatty acid synthesis and metabolism were analysed by real-time PCR.

Results: Sterol regulatory element-binding protein 2 (SREBP2) showed lower expression in EFAD pups than in controls $(0.50 \pm 0.04$ and $0.91 \pm 0.09, \mathrm{p}<0.01$ ), while SREBP1a and $\mathrm{c}$ not differed. The expression of fatty acid synthase (FAS) was also lower than in control pups $(0.12 \pm 0.03$ and $0.74 \pm 0.15$ respectively, $\mathrm{p}<0.01)$. StearoylCoA desaturase (SCD)-1 did not differ between the EFAD and control pups $(0.14 \pm 0.03$ and $0.20 \pm 0.07)$, but SCD-2 was increased in the liver of EFAD pups $(0.97 \pm 0.12$ and $0.67 \pm 0.12, p<0.01)$. Fatty acid binding protein (FABP) $1(0.08 \pm 0.04$ and $0.71 \pm 0.44, \mathrm{p}<0.01)$ and FABP4 $(1.27 \pm 0.29$ and $2.14 \pm 0.61, \mathrm{p}<0.02)$ were also lower in EFAD pups.
Summary: Most genes investigated related to lipid metabolism were downregulated by perinatal EFA deficiency. It remains to determine if our results are associated with the resistance to obesity in the adult animals.

\section{P29 Expression of Free Fatty Acid Receptor
GPR40 in the Central Nervous System of
Adult Monkeys}

D. Ma, B. Tao, S. Warashina, S. Kotani, L. Lu, D.B. Kaplamadzhiev, Y. Mori, T. Yamashima, A.B. Tonchev

'Department of Restorative Neurosurgery, Kanazawa University, Japan, ${ }^{2}$ Department of Neurosurgery, Shanghai Jiao Tong University School of Medicine, Shanghai, PRC, ${ }^{3}$ Division of Cell Biology, Varna University of Medicine, Varna, Bulgaria

The G-protein coupled receptor 40 (GRP40) is a transmembrane receptor for free fatty acids, and is known for its relation to insulin secretion in the pancreas. Recent studies demonstrated that spatial memory and hippocampal long-term potentiation of rodents and cognitive function of humans are improved by a dietary supplementation with arachidonic and/or docosahexaenoic acids, which are possible ligands for GPR40. While free fatty acid effects on the brain might be related to GPR40 activation, the role of GPR40 in the central nervous system (CNS) is at present not known. Here we studied expression and distribution of GPR40 in CNS of adult monkeys by immunoblotting and immunohistochemstry. Immunoblotting analysis showed a band of approximately $31 \mathrm{KDa}$ consistent with the size of GPR40 protein. GPR40 immunoreactivity of was observed in the nuclei and/ or perikarya of a wide variety of neurons including neurons in the cerebral cortex, hippocampus, amygdala, hypothalamus, cerebellum, and spinal cord. In addition, astrocytes of the cerebral white matter, the molecular layer and multiform layer of the cerebral cortex, the subventricular zone along the anterior horn of the lateral ventricle, and the subgranular zone of the hippocampal dentate gyrus showed GPR40 immunoreactivity. The present data first provide a morphological basis for clarifying the role of GPR40 in the primate CNS.
86

J Nutrigenet Nutrigenomics 2008;1:59-90 1st Congress of the International Society of Nutrigenetics/Nutrigenomics (ISNN) 


\section{P30 \\ No Significant Association between the Polymorphisms of Inwardly Rectifying Potassium Channel Gene and Type 2 Diabetes in Chinese Han Population}

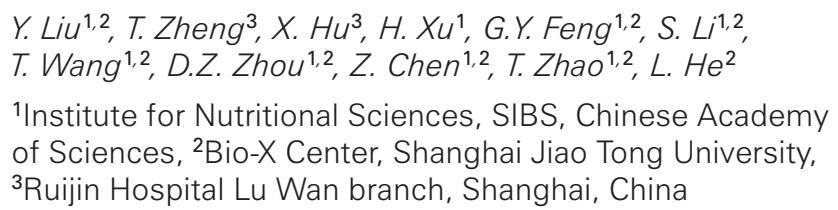

Objective: ATP-sensitive potassium (K-ATP) channels play a central role in glucose-stimulated insulin secretion from pancreatic beta cells. The K-ATP channel comprises two subunits, the inwardly rectifying potassium channel Kir6.2 (KCNJ11) and the sulfonylurea receptor SUR1 (ABCC8). Several polymorphisms (especially E23K and $\mathrm{I337V}$ ) in $\mathrm{KCNJ} 11$ have been reported to be associated with type 2 diabetes in various ethnic populations. We carried out a study to explore the association between polymorphisms within KCNJ11 (Rs5215 and rs5219) and type 2 diabetes in Chinese Han population. Materials and methods: 609 unrelated individuals with Type 2 diabetes (222 males and 387 females with a mean age of 67.3 years, $\mathrm{SD}=11.0)$ and 381 control subjects ( 119 males and 262 females with a mean age of 56.2 years, $\mathrm{SD}=12.4$ ) were recruited in Shanghai. Type 2 diabetes was defined as fasting plasma glucose value $>7.0$ $\mathrm{mmol} / 1$, or $2 \mathrm{~h}$ postprandial glucose $>11.1 \mathrm{mmol} / 1$. Control subjects had a fasting plasma glucose concentration $<6.1 \mathrm{mmol} / \mathrm{l}$. Written informed consent was obtained from the participants. Genomic DNA was prepared from venous blood using standard phenol chloroform extraction. Polymerase chain reaction (PCR) was performed on the GeneAmp PCR system 9700 (Applied Biosystems). All the SNPs were sequenced on the ABI 3100 genetic analyzer using the ABI PRISM BigDye Terminator Cycle Sequencing Kit (Applied Biosystems). Rs5215 and rs5219 were genotyped in 987 subjects. Result: The genotype distributions of rs5215 and rs5219 were in Hardy-Weinberg equilibrium. The frequencies of allele and genotypes in Chinese Han population are similar to those in the Japanese and Korean populations. No statistical association was shown between each SNP and the risk of Type 2 diabetes by logistic regression analysis after adjusting for age, sex and BMI (for genotypes, adjusted $\mathrm{P}=0.45$ and adjusted $\mathrm{P}=0.60$, respectively). We constructed haplotypes with the two markers and found that two common haplotypes accounted for about $95 \%$ of those observed. However, no significant association with Type 2 diabetes (Global $\mathrm{p}=0.20$ ). Conclusions: Rs5215 and rs5219, the two polymorphisms in KCNJ11 are not associated with Type 2 diabetes in Chinese Han population.

\section{P31 \\ Proteomic Profile of Subcutaneous Adipose Tissue in Normoglycemic and Hyperglycemic Morbidly Obese Patients}

\author{
C. Zabena, P. Mateos-Cáceres\#, A. Corbaton, \\ J. Alvarez Fernández-Represa*, A. Torres-García* \\ A. López-Farré\#, M. Serrano-Ríos \\ Departments of Medicine and Surgery*. Cardiovascular \\ Institute \#. Hospital Clinico San Carlos, Madrid. Spain
}

Objective: 1- To establish a proteomic profile of the subcutaneous adipose tissue in morbidly obese in order to compare and to identify the protein expression profile in two groups of the patients: subjects with normoglycaemia and with hyperglycemia (impaired fasting glucose (IFG)/diabetes).

Methods: 19 unrelated subjects (14 females, $73.7 \%$ ) morbid obese underwent bariatric surgery. 10 (52.6\%) normoglycemic, group A; and 9 (47.4\%) hyperglycemic subjects (group B). Weight, height, waist, SBP, DBP were measured. BMI $(\mathrm{kg} / \mathrm{m} 2)$ was calculated. Fasting glucose, lipid profile, proinsulin, insulin, leptin, adiponectin (RIA) were determined. Insulin resistance calculated by HOMA. Adipose tissue samples were taken during the bariatric surgery from abdominal subcutaneous at the beginning of surgery. Protein lysates, quantified by BCA technique, were separated and compared using bidimensional electrophoresis (IPG 4-7, 17cm). Gels were stained with silver-nitrate.

Results: Anthropometrical and biochemical characteristics were similar in group A and B. Subjects with hyperglycaemia have increased expression of 4 isoforms of Protein disulphide isomerase (PDI), but isoform 3 was significantly increased. Moreover, the expression of isoform 4 of transferin was significantly increased and one of 5 isoforms of Heat Shock Protein (HSP) was also significantly increased as compared with normoglycaemic subjects. Proteins with cytoskeletal (actin) or proteins associated with metabolic functions (glutathione s transferase) have similar expression in both groups.

Conclusion: Our results suggest that hyperglycemia is associated with increased expression of proteins related with endoplasmic reticulum and redox functions (PDI), proteins involve in the response of stress, such as HSP, and transferrin.

\section{P32 \\ Expression of Cidea in Adipose Tissue of Spanish Morbidly Obese Patients \\ C. Zabena, A. Torres-Garcia*, J.L. Gonzalez-Sanchez, M.T. Martínez-Larrad, J. Alvarez Fernández-Represa*, M.J. Martínez-Calatrava, A. Corbaton, C. Fernández, M. Serrano-Ríos \\ Departments of Medicine and Surgery*. Hospital Clinico San Carlos, Madrid. Spain}

Objective: To analyze the Cell death-inducing DFFA [DNA fragmentation factor-alpha]-like effector A (CIDEA) expression in subcutaneous adipose tissues (SAT) and visceral adipose tissue (VAT) in morbidly obese patients and its correlations with different degrees of 
glucose tolerance and obesity. Methods: Subjects: 1) 41 unrelated (31 females, $75.6 \%$ ) morbidly obese patients underwent bariatric surgery and 2) controls: 3 patients ( 2 females, $66.7 \%$ ) undergoing surgery for benign conditions. Anthropometrical measurement. Fasting glucose, lipid profile, insulin, leptin, adiponectin (RIA) were determined. Insulin resistance (IR): HOMA. (HOMA IR Spanish population 33.8). Metabolic Syndrome (MS):IDF criteria. Obese group: Abdominal SAT/VAT samples. Controls: SAT. Adipose Tissue: Total RNA: extracted with a commercial kit (QIAGEN Kit). cDNA synthesized:random hexamers primers. Quantitative PCR was performed in 7900HT Applied Biosystems using specific primers and probes (TaqMan). Five of twenty target genes (previously reported to be relevant to IR, obesity, and MS.CIDEA, PPAR- $\gamma$, TNF- $\alpha$, adiponectin, adiponectin receptor 1- ADIPO-R1) were analyzed specifically studied and housekeeping genes ( $\beta$-actin). Relative quantification: $\Delta \Delta \mathrm{Ct}$ method. ANOVA and Pearson's correlations, univariate analysis were performed as appropriate (SPSS 12.0). Results: Obese group: impaired fasting glucose/ diabetes type 2: 24 patients (58.5\%), IR: 32 (78.1\%); MS 23 (56.1\%). SAT mRNA expression of CIDEA was decreased in morbidly obese patients as compared to controls $(p=0.025)$. CIDEA's SAT expression was decreased in obese with IR as compared to those without it $(p=0.012)$, but no differences were found between obese with/without abnormal glucose status, nor with individual components of MS nor with some of the investigated variables (adiponectin, leptin). SAT CIDEA mRNA expression was positively correlated with mRNA expression of PPAR- $\gamma$, adiponectin, and ADIPO-R1 genes but not with TNF- $\alpha$.In obese individuals VAT/SAT CIDEA's expression was comparable. Conclusions: 1- CIDEA's expression was demonstrated, by the first time, in VAT obese humans. 2- CIDEA gene expression was decreased in SAT in morbidly obese, particularly in those with IR. 3- SAT CIDEA's expression parallels that of insulin sensitivity related genes (PPAR- $\gamma$, adiponectin, ADIPO-R1) suggesting its potentially relevant role in the regulation of substrate homeostasis (glucose /lipid).

\section{P33 \\ Concentration of Zinc, Selenium and Copper in Serum and Tumor Cytosols of Breast Cancer Patients: The Inhibitory Effect on Telomerase Gene Expression in Breast Cancer Cell Lines}

\author{
N. Zarghami ${ }^{1}$, J. Asadi² \\ ${ }^{1}$ Department of Clinical Biochemistry and RIA, Drug \\ applied Research Center, Tabriz university of Medical \\ Sciences, Tabriz, ${ }^{2}$ Department of Biochemistry and \\ Nutrition, Nutritional Reaserch Center, Tabriz University Of \\ Medical Sciences, Tabriz, Iran
}

Background and Objectives: Breast cancer is the most common cancer in women. The aim of this study was to evaluate Zinc, Selenium and Copper in serum and tumor cytosol extracts and the inhibitory effect of these elements on telomerase gene expression in breast cancer cell lines.

Material and Method: This study was composed of 32 women with breast cancer and 24 with benign tumors. The levels of $\mathrm{Zn}, \mathrm{Cu}$ and selenium in serum and tumor cytosol extracts were measured using atomic absorption spectroscopy (AAS) and Graphic atomic absorption spectroscopy. Relative telomerase activities (RTA) of tissue and cell line were measured by TRAP assay.

Results: Mean serum levels of $\mathrm{Zn}, \mathrm{Cu}$ and $\mathrm{Se}$ in malignant tumors were $0.969 \pm .19,1.47 \pm .48 \mathrm{mg} / \mathrm{L}$ and $60.04 \pm 23.38 \mathrm{respec}-$ tively. However, benign tumors had $1.07 \pm .35,1.09 \pm .20 \mathrm{mg} / \mathrm{L}$ and $92.42 \pm 18.70 \mu \mathrm{g} / \mathrm{L}$, respectively. The ratio of $\mathrm{Cu} / \mathrm{Zn}$ in malignant and benign tumors was 1.52 and 1.12 , respectively. There was a significant difference between malignant and benign tumors $(\mathrm{P}<0.001)$. Mean levels of $\mathrm{Zn}$ and $\mathrm{Cu}$ in malignant tumor cytosols were $66.75 \pm 72.5$ and $28.29 \pm 3.84 \mu \mathrm{g} / \mathrm{g}$ respectively. Benign tumor cytosols had $26.7 \pm 28.5$ and $21.02 \pm 6.08 \mu \mathrm{g} / \mathrm{g}$ respectively. The difference between benign and malignant tumor cytosols was statistically significant $(\mathrm{P}<0.002)$. The ratio of $\mathrm{Cu} / \mathrm{Zn}$ in benign and malignant tumor cytosols was 0.42 and 0.79 respectively. This difference was statistically significant $(\mathrm{P}<0.001)$. The mean concentrations of Se in malignant and benign breast tumors were $1.05 \pm 0.42 \mu \mathrm{g} / \mathrm{g}$ and $0.51 \pm 0.22 \mu \mathrm{g} / \mathrm{g}$ respectively. This difference was statistically significant $(\mathrm{P}<0.01)$. Relative telomerase activity (RTA) in malignant and benign tumor tissues was 93.75 and 8 respectively. In kinetic and dose dependent experiments on $47 \mathrm{D}$ breast cancer cell line, it was revealed that at lower doses, $\mathrm{Zn}(100 \mu \mathrm{M} / \mathrm{L})$ and $\mathrm{Cu}(3 \mu \mathrm{M} / \mathrm{L})$ had 3.6 to 5.2 fold increased telomerase activity but in high dosed (500 and $10 \mu \mathrm{M} / \mathrm{L}$ ), there was a remarkable decrease in telomerase activity. The cell line after being treated with 10, 30 micromole/L selenium-1methuonin, telomerase activity was markedly inhibited $(\mathrm{p}<0.001)$

Conclusion: It is speculated that changes of $\mathrm{Se}, \mathrm{Zn}$ and $\mathrm{Cu}$ may have biological role in tumor progression and/or repression. The inhibitory effect on telomerase gene expression in breast cancer cell lines could be a target for therapeutic purpose. 


\section{Author Index}

\section{Journal of \\ Nutrigenetics Nutrigenomics}

Numbers refer to abstract number

\author{
Abbasalizad Farhanghi, M. P22 \\ Adra, N. P9 \\ Ajudua, S. A12 \\ Alvarez Fernández-Represa, J. \\ P31, P32 \\ Amini, H. P11 \\ Andreoli, A. P5 \\ Arbo, I. A8 \\ Arnett, D. P23 \\ Asadi, J. P17, P33 \\ Atkin, W.S. A23
}

Barnett, M.P.G. P1, P19

Barraclough, D. P1

Batal, M. P9

Benassi, B. P20

Bingham, S.A. A23

Bishop, D.T. A23

Blum, K. P18

Brännäs, E. P24

Brattbakk, H.-R. A8

Braverman, E.R. P18

Burguete, C. P2

Butts, C. P19

Calabrese, E. A14

Cale, C.Q. A30

Cardwell, C. A23

Carrasco, P. P2

Carroll, P. P16

Cecil, T. A23

Chamari, M. P11

Chen, Z. P30

Chew, E.Y. A12

Clavero, J.C. A14

Clemons, T.E. A12

Clifton, P. P20

Collins, L.J. A18

Cooney, J. P1

Cooper, J.A. A6, P27

Corbaton, A. P31, P32

Corella, D. P2

da Costa, M.I.U. P3

da Cruz, I.B.M. P3

da Cruz Jung, I.E. P3

Davies, A. A27

Davy, M. P1

de Bartolomeo, G. A14

De Caterina, R. A5

De Lorenzo, A. P5

De Lorenzo, D. P4

de Lorgeril, M A20 de Meester, F. A28

Dedoussis, G.V. A19

Delgado-Lista, J. P23

Di Renzo, L. P5

Díaz, M.E. P25

Dimitrov, D. A16, P10

Djazayery, A. P6, P11

do Prado Lima, P.A.S. P3

Dommels, Y.E.M. P19

Downs, B.W. P18

Drenos, F. A11, P27

El Khoury, D. P9

Elashoff, M. A12

Estruch, R. P2

Eustathiou, E. A19

Evaggelidaki, E. A19

Fan, Z. P12

Farmaki, A.-E. A19

Fay, L.B. A29

Fenech, M. P20

Feng, G.Y. P30

Fernández, C. P32

Ferrari, S. A13

Gabrielsson, B. P28

Gallou-Kabani, C. A2

Garcia-Bailo, B. P23

Ge, D. P21

Ghiasvand, R. P6

Gill-Garrison, R. A14

Gjøen, T. P24

Gonzalez-Sanchez, J.L. P32

Gosslau, A. P7

Grimaldi, K. A14

Guillem-Sáiz, P. P2

Guillén, M. P2

Hamet, P. A9

Hart, D.J. A18

Hatzopoulou, I. A19

He, L. P30

Hedderley, D. P19

Henning, A.K. A12

Hosseini, M. P6, P11

$\mathrm{Hu}, \mathrm{X} . \mathrm{P} 30$

Hughes-Fulford, M. A22

Humphries, S.E. A6, A11, P27

Hunt, S.C. A10

Hussein, L. P8

Hwalla, N. P9
Ivanova, D. P10

Jalali, M. P6, P11

Jazayeri, S. P11

Jimenez, S. P25

Johansen, B. A8

Junien, C. A2

Kähönen, M. P14

Kamal-Eldin, A. P24

Kambouris, M. A17, P16

Kaplamadzhiev, D.B. P29

Kapravellou, G. A19

Kazdová, L. A9

Ke, Z.-J. P12

Keshavarz, S.A. P6, P11

Kewer, C. P3

Kiselova, Y. P10

Komninou, D. P13

Kornman, K. A27

Kotani, S. P29

Koutsouris, D. A14

Křen, V. A9

Křenová, D. A9

Kulseng, B. A8

Kyriakou, T. A18, P21

Laaksonen, M. P14

Laing, W. P1

Langaas, M. A8

Lee, A.K. P21

Lehtimäki, T. P14

Li, H. A25, P15

Li, S. P30

Li, Y. A26

Lin, X. A25, P15

Lindberg, F. A8

Liu, G. P21

Liu, Y. P30

Look, M. A14

Loos, R. A25, P15

López-Farré, A. P31

Lopez-Miranda, J. P23

Lopez-Segura, F. P23

Louizou, E. A19, P16

Lu, L. P29

Luo, J. P12

Ma, D. P29

Macklin, C.P. A23

McNabb, W.C. P1, P19

Madonna, R. A5

Mahboob, S.A. P17, P22
Marinos, S. A14

Martell, S. P19

Martínez-Calatrava, M.J. P32

Martínez-Larrad, M.T. P32

Massaro, M. A5

Mateos-Cáceres, P. P31

Meshkin, B. P18

Mezitis, N.H.E. P13

Mikkilä, V. P14

Milner, J. A21

Mitrou, P.N. A23

Moazzami, A. P24

Montgomery, H. A11

Mori, Y. P29

Mougiakakou, S. A14

Muntoni, S. A24

Muntoni, Sa. A24

Mutch, D.M. A4

Muthumala, A. A11

Noakes, M. P20

Nones, K. P19

Obeid, O. P9

O'Callaghan, N. P20

O'Dell, S.D. A18, P21

Omenn, G.S. A3

Ordovas, J.M. A7, P23

Ortega, C. P2

Ostad Rahimi, A. P22

Palmen, J. P27

Palsdottir, V. P28

Papoutsakis, C. A19

Park-Ng, Z. P19

Patescia, R. A14

Peet, M. P11

Perez-Jimenez, F. P23

Perez-Martinez, P. P23

Pérusse, L. A15

Pickova, J. P24

Piperis, T. A14

Presswood, E. P27

Prihoda, T.J. P18

Primrose, J. A23

Printzos, M. A14

Raitakari, O.T. P14

Randolph, K. A27

Räsänen, L. P14

Richie, J.P. P13

Rodríguez-Ojea, A. P25

Rogus, J. A27

\section{KARGER}

(c) 2007 S. Karger AG, Basel

Fax +41613061234

E-Mail karger@karger.ch

www.karger.com 
Roh-Schmidt, H. A27

Romero, A.C.S. A14

Rowe, S. A32

Roy, N.C. P1, P19

Ruyter, B. P24

Sakka, S. A19

Salas, J. P2

Saleh, A. P8

Samiotakis, M. P16

SanGiovanni, J.P. A12

Savas, B.S. A31

Schwanke, C.H.A. P3

Scioli, A. A14

Šeda, O. A9

Šedová, L. A9

Serrano-Ríos, M. P31, P32

Shapira, N. P26
Sibai, A.-M. P9

Simopoulos, A.P. A1

Smart, M. P27

Snieder, H. A18, P21

Sorlí, J. P2

Sotos, M. P2

Spector, T.D. A18, P21

Stoffel-Wagner, B. A14

Straka, R. P23

Strandvik, B. P28

Sun, C.-H. A26

Tagaris, T. A14

Talmud, P.J. A6, P27

Tao, B. P29

Tehranidoost, M. P11

Tonchev, A.B. P29

Torres-García, A. P31, P32
Trattner, S. P24

Tremblay, J. A9

Tsai, M. P23

Tzirkalli, M. A19

Vidra, N.V. A19

Vigé, A. A2

Vora, A. A12

Waite, R.L. P18

Wang, B. P12

Wang, T. P30

Wang, X. A18, P12

Warashina, S. P29

Watson, M.A. A23

White, L. P18

Wickman, A. P28

Wu, Y. A25, P15
Xu, H. P30

Yamama, G. P8

Yamashima, T. P29

Yannakoulia, M. A19

Yiannakouris, N. P23

Zabena, C. P31, P32

Zarghami, N. P17, P33

Zhao, T. P30

Zheng, T. P30

Zhou, D.Z. P30

Zhou, X.-R. A26

Zhu, S. P19

Zhu, S.T. P1

Zur, B. A14 